\title{
Thermal and chemical vapor deposition of Si nanowires: Shape control, dispersion, and electrical properties
}

\author{
A. Colli, ${ }^{\text {a) }}$ A. Fasoli, P. Beecher, P. Servati, ${ }^{\text {b) }}$ S. Pisana, Y. Fu, A. J. Flewitt, W. I. Milne, \\ and J. Robertson \\ Department of Engineering, University of Cambridge, Cambridge CB3 OFA, United Kingdom \\ C. Ducati \\ Department of Materials Science and Metallurgy, University of Cambridge, Cambridge CB3 6GF, \\ United Kingdom
}

\section{S. De Franceschi}

Laboratoire de Transport Electronique Quantique et Supraconductivité, CEA-Grenoble, 38054 Grenoble cedex 9, France

\author{
S. Hofmann and A. C. Ferraric) \\ Department of Engineering, University of Cambridge, Cambridge CB3 OFA, United Kingdom
}

(Received 21 March 2007; accepted 14 June 2007; published online 6 August 2007)

\begin{abstract}
We investigate and compare complementary approaches to SiNW production in terms of yield, morphology control, and electrical properties. Vapor-phase techniques are considered, including chemical vapor deposition (with or without the assistance of a plasma) and thermal evaporation. We report Au-catalyzed nucleation of SiNWs at temperatures as low as $300{ }^{\circ} \mathrm{C}$ using $\mathrm{SiH}_{4}$ as precursor. We get yields up to several milligrams by metal-free condensation of $\mathrm{SiO}$ powders. For all processes, we control the final nanostructure morphology. We then report concentrated and stable dispersions of SiNWs in solvents compatible with semiconducting organic polymers. Finally, we investigate the electrical response of intrinsic SiNWs grown by different methods. All our SiNWs exhibit $p$-type behavior and comparable performance, though in some cases ambipolar devices are observed. Thus, processing and morphology, rather than the growth technique, are key to achieve optimal samples for applications. (C) 2007 American Institute of Physics. [DOI: 10.1063/1.2764050]
\end{abstract}

\section{INTRODUCTION}

The bottom-up synthesis of one-dimensional (1D) semiconducting nanostructures has attracted increasing interest in recent years both for fundamental physics and for potential device applications. ${ }^{1-8}$ On the one hand, the capability to synthesize nanoscale building blocks without the need of expensive and time-consuming lithography techniques offers key opportunities for high-integration nanoelectronics. Research is therefore heading towards the realization of singlenanowire (NW) or crossed-NW devices with the aim of integrating a large number of active components into a rational geometry. ${ }^{3-5,9,10}$ On the other hand, applications are envisaged where nanostructured materials do not require individual manipulation but are assembled as bulk, while individually retaining their nanoscale properties such as quantum confinement or large surface-to-volume ratio. ${ }^{6-8,11,12}$ As a consequence, several synthesis approaches are being developed to match the specific requirements of different possible applications. Bulk production of nanocrystals (both in solution $^{13,14}$ or from the vapor phase ${ }^{15,16}$ ) for post-growth manipulation has received as much attention as the selective and oriented growth of NWs directly into devices. ${ }^{17,18}$

$\mathrm{Si}$ nanowires (SiNWs) are particularly relevant due to

\footnotetext{
a)Electronic mail: ac458@cam.ac.uk

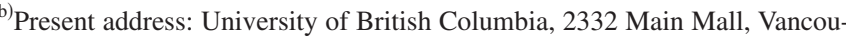
ver, BC V6T 1Z4, Canada.

${ }^{c)}$ Electronic mail: acf26@eng.cam.ac.uk
}

the central role of Si in the semiconductor industry. Deposition techniques for SiNWs include laser ablation ${ }^{16,19}$ high temperature thermal evaporation, ${ }^{20-22}$ molecular beam epitaxy (MBE) ${ }^{23}$ chemical vapor deposition (CVD) ${ }^{24-26}$ and plasma-enhanced CVD (PECVD). ${ }^{27}$

CVD is probably the most investigated synthesis technique for SiNWs. ${ }^{24-26}$ Generally, a metal nanoparticle is required to favor selective decomposition of the precursor gas and the consequent nucleation of substrate-bound 1D nanostructures. ${ }^{28,29}$ By patterning the catalyst on oriented crystalline substrates, defined and oriented arrays of SiNWs have been fabricated. ${ }^{26}$ This highlights the potential of the CVD approach for the realization of bottom-up nanoscale devices, where active components are no longer manufactured but grown from point to point in a controlled fashion. In this framework, however, the fabrication step involving NW synthesis must be compatible with the whole process flow. This implies, for example, that the NW growth temperature must be low enough to ensure compatibility with the final device substrate. Efforts are therefore addressed to fully understand the physics and chemistry behind the growth of semiconductor NWs and to explore the lowest growth temperature achievable by the metal-assisted mechanism. ${ }^{30-34}$

Bulk production is emerging as an alternative approach for the fabrication and assembly of NWs in large quantities. Several growth strategies have been proposed to achieve large-scale SiNW growth, most of them still requiring the presence of a metal catalyst to promote 1D nucleation. ${ }^{16,19-22}$ 
With process temperatures usually exceeding $1000{ }^{\circ} \mathrm{C}$, Au, $\mathrm{Fe}, \mathrm{Ga}$, and $\mathrm{Sn}$ are mixed to the $\mathrm{Si}$ precursor vapor either by thermal evaporation or laser ablation. NWs are collected from the furnace reactor in form of woolenlike bundles. ${ }^{19,20}$

There is a need, however, to avoid the metal contamination potentially arising from the residual catalyst particles. Removing the catalyst postgrowth may require complex and expensive purification treatments. ${ }^{35}$ The so-called oxideassisted growth $(\mathrm{OAG})$ method provides a viable alternative for metal-free bulk production of SiNWs. ${ }^{15,36}$ Reference 37 reported the production of milligrams of SiNWs by thermal evaporation of $\mathrm{SiO}$. It was suggested that $\mathrm{SiO}$ triggers the self-assembly of SiNWs, based on the observation that pure $\mathrm{Si}$ or pure $\mathrm{SiO}_{2}$ as precursor materials gave negligible yield. ${ }^{38}$ Indeed, a $\mathrm{SiO}_{x}(x>1)$ thin film $(\sim 1.3 \mathrm{~nm})$ was also found to promote the metal-free nucleation of InAs NWs, ${ }^{39,40}$ although it was not clear in this case if this process could be explained by the oxide-assisted growth model of Ref. 15. To date, evaporation of $\mathrm{SiO}$ (or mixtures of $\mathrm{Si}$ and $\mathrm{SiO}_{2}$ ) still remains the most flexible and reliable approach to metal-free SiNW synthesis. ${ }^{37,38,41}$ This method, however, has limitations for the shape control and uniformity of the resulting nanostructures. Thin and crystalline SiNWs are often coupled with partially or fully oxidized structures, resulting in crystalline $\mathrm{Si}$ spheres connected into chains by $\mathrm{SiO}_{2}$ bridges of variable length. ${ }^{42-44}$ References 42 and 43 linked such shape variation to the local condensation temperature. They proposed a two-step growth dynamics where SiNW formation is followed by thermal oxidation of the crystalline $\mathrm{Si}$ cores. This was motivated by the observation of an increasing fraction of oxidized nanochains in the hotter regions of the furnace tube. ${ }^{42}$ Shape separation of as-grown NW bundles requires further processing. Ideally one should engineer and optimize the synthesis to achieve $100 \%$ yield of the desired nanostructure morphology.

Thermal evaporation in an inert gas flow (commonly called vapor transport) is suitable for bulk production of several nanomaterials. ${ }^{15,45,46}$ The main advantages of vapor transport are its versatility, the use of a relatively cheap experimental setup, and the fact that NW bundles of different materials can be easily synthesized without the need of potentially dangerous precursor gases, such as $\mathrm{SiH}_{4}$. On the other hand, the high temperatures involved in the process do limit the substrate selection. NWs prepared by this technique are suitable for postgrowth processing, typically via dispersion in solution. Yet, very few studies have so far focused on SiNW suspensions, ${ }^{47-50}$ despite the fact that this is one of the main research topics in the carbon nanotube community. ${ }^{35,51-53}$ In most cases, solution processing was investigated just as a simple step toward dispersion of individual, as-grown NWs on solid substrates for transmission electron microscopy (TEM) or electrical characterization. ${ }^{3,21}$ However, many emerging applications (for example, hybrid inorganic/organic composites ${ }^{54,55}$ ) require handling of highdensity suspensions of NWs or nanocrystals, together with controlling on demand the chemical properties of the resulting solution.

A key step to evaluate the NW suitability for applications is the assessment of their electrical properties. It is sometimes claimed that the use of SiNWs would result in transistor performances well above existing technologies, in terms of mobility, trans-conductance, on/off ratio, etc. ${ }^{8,18,56}$ However, the reported values for SiNW hole mobility (extracted from the transfer subthreshold slope and using a simple cylindrical model to estimate the NW capacitance) are so far widely scattered from $\sim 10$ to $1350 \mathrm{~cm}^{2} / \mathrm{V} \mathrm{s}^{2,8,18,41,56}$ Also, it is difficult to precisely estimate the doping concentration in NW channels. Many report SiNWs lightly or heavily doped. ${ }^{57-59}$ However, not many investigations focus on nominally intrinsic NWs. ${ }^{57,60,61}$ Also, a variety of different metals have been tested to contact $\mathrm{SiNWs}$, such as $\mathrm{Al} / \mathrm{Au}, \mathrm{Ni}, \mathrm{Ti} / \mathrm{Al}, \mathrm{Ti} / \mathrm{Au}$, and $\mathrm{Cr} / \mathrm{Au}, 3,56,57,60-62$ and different annealing or passivation protocols have been implemented. ${ }^{3,56,60-62}$ Because of this, a direct comparison of reports on electrical properties, even when the same growth technique is utilized, is difficult. Indeed, scattered values for basic transistor parameters have been presented in literature for nominally equivalent SiNW channels (see, for example, the properties review in Ref. 62).

Thus, in this paper we perform an extensive characterization and comparison of SiNWs grown by different techniques. We demonstrate selective synthesis of NWs and nanocones (NCs) down to $300{ }^{\circ} \mathrm{C}$ by CVD and PECVD, and assess the effect of several growth parameters in such low temperature nucleation regime. We also report the production of bulk quantities of SiNWs by thermal evaporation, with and without the use of a metal catalyst. We show how to achieve shape control in oxide-assisted growth and stable SiNW dispersions in different solvents. Finally, we compare the electrical properties of all types of SiNWs by using the same device geometry and fabrication process. In particular, we focus on intrinsic SiNWs and observe preferential holeaccumulation behavior, though ambipolar field-effect transistors (FETs) are also obtained. Device response and performance appear to be dominated neither by the particular synthesis process nor by the use of a metal catalyst.

\section{EXPERIMENT}

Both metal-seeded and metal-free growth of SiNWs are investigated. A quartz cylinder $4 \mathrm{~cm}$ in length and $5 \mathrm{~cm}$ in diameter acts as support for metal-free NW condensation. This allows easy unloading and collection of the as-grown material. For metal-assisted growth, commercial Si substrates are coated and patterned with thin $\mathrm{Au}$ layers $(0.5 \mathrm{~nm}) .^{27} \mathrm{Au}$ is deposited by evaporating the precursor metal $(99.99 \%)$ from a ceramic boat in a standard evaporator at a base pressure below $10^{-6}$ mbar. The thickness of the $\mathrm{Au}$ layer is determined by an in situ quartz crystal.

Low temperature, catalytic (PE)CVD growth is performed in an Oxford Instruments $\mu \mathrm{P}$ reactor, at a base pressure of $1 \times 10^{-6}$ mbar. Au-coated Si substrates are heated to $300{ }^{\circ} \mathrm{C}$, as monitored by a thermocouple in direct contact with the substrate surface. Then, pure $\mathrm{SiH}_{4}$ or $\mathrm{H}_{2}$-diluted $\mathrm{SiH}_{4}$ is admitted with various flow rates. The total pressure is varied between $200 \mathrm{mTorr}$ and 10 Torr. A $13.6 \mathrm{MHz}$ rf power $(5-30 \mathrm{~W})$ is used to create a plasma, when needed.

High temperature, metal-assisted growth of SiNWs are 
studied by means of a thermal evaporation process in a furnace, at a base pressure of $\sim 10^{-3}$ mbar. Pure Si powders are placed in an alumina boat and heated up to $1150-1250{ }^{\circ} \mathrm{C}$. The Si vapor is carried downstream by a 100 SCCM (cubic centimeter per minute at standard temperature and pressure) $\mathrm{Ar}$ flow and condenses along the colder regions $\left(750-850{ }^{\circ} \mathrm{C}\right)$ of the furnace tube where the Au-coated substrates are placed. The Ar pressure is set to 100 mbars during growth and 1 bar during the temperature ramps, to provide pressure-based growth interruptions and avoid non steadystate effects. ${ }^{45}$ For oxide-assisted growth, $\mathrm{SiO}$ powders are evaporated at $1400{ }^{\circ} \mathrm{C}$ in an alumina tube, in the presence of a $50 \mathrm{SCCM}$ Ar flow (400-800 mbars). The $\mathrm{SiO}$ vapor is found to condense sharply in form of NW bundles at $950{ }^{\circ} \mathrm{C}$.

For simplicity, in this paper we will refer to type I when reporting Au-assisted SiNWs synthesized in a vacuum CVD reactor using $\mathrm{SiH}_{4}$ as precursor gas, type II to Au-assisted SiNWs grown by thermal evaporation of Si powders, and type III to SiNW deposition by oxide-assisted metal-free growth performed in the same furnace as type II.

Au-coated quartz substrates are characterized by UVvisible absorption spectroscopy (Perkin Elmer Lambda 950 spectrophotometer). As-produced NWs are characterized by field-emission scanning electron microscopy (FESEM), TEM, and x-ray diffraction (XRD). Three-terminal FETs are fabricated by dispersing SiNWs on a 200-nm-thick $\mathrm{SiO}_{2}$ layer thermally grown on a degenerate $p$-doped $\mathrm{Si}$ wafer, used as backgate. Source and drain contacts are defined by e-beam or x-ray lithography. After a short etching in buffered $\mathrm{HF}$ to remove the NW oxide shell, interdigitated $\mathrm{Ti} / \mathrm{Al}$ contacts $(20 / 90 \mathrm{~nm})$ are deposited by e-beam evaporation. No contact annealing is performed to avoid any further treatment of as-grown SiNWs.

\section{NANOWIRE GROWTH}

\section{A. Substrate preparation}

$\mathrm{Au}$ thin films dewet at elevated temperatures $\left(>300{ }^{\circ} \mathrm{C}\right)$ forming a distribution of isolated catalyst nanoparticles. ${ }^{63,64}$ Dewetting initiates at grain boundaries and edges through surface diffusion, and the metal can remain crystalline. ${ }^{64}$ The film restructuring and the final shape of the catalyst islands are a result of surface and interface energy minimization. The optical absorption of small metal clusters is strongly size and geometry dependent. ${ }^{63,65,66}$ The surface plasmon of colloidal gold lies in the visible region, ${ }^{63,66}$ which allows the restructuring of the Au film to be monitored by UV-visible spectroscopy.

Figure 1 shows the adsorption spectra of an asevaporated 0.5 -nm-thick Au film on quartz, as well as of 0.5 -nm-thick Au annealed at 300 and $500{ }^{\circ} \mathrm{C}$ in vacuum. The absorption spectrum of $20 \mathrm{~nm}$ Au colloids dispersed on quartz is plotted for comparison. The as-evaporated Au film shows a broad peak centered around $550 \mathrm{~nm}$, which clearly blueshifts to $526 \mathrm{~nm}$ upon annealing at $300{ }^{\circ} \mathrm{C}$. The SEM analysis of patterned $\mathrm{Au}$ films on $\mathrm{SiO}_{2}$ annealed at $300{ }^{\circ} \mathrm{C}$ (Fig. 1, inset) indicates that arrays of quasispherical nanoparticles, $10-30 \mathrm{~nm}$ in diameter, form on the surface.

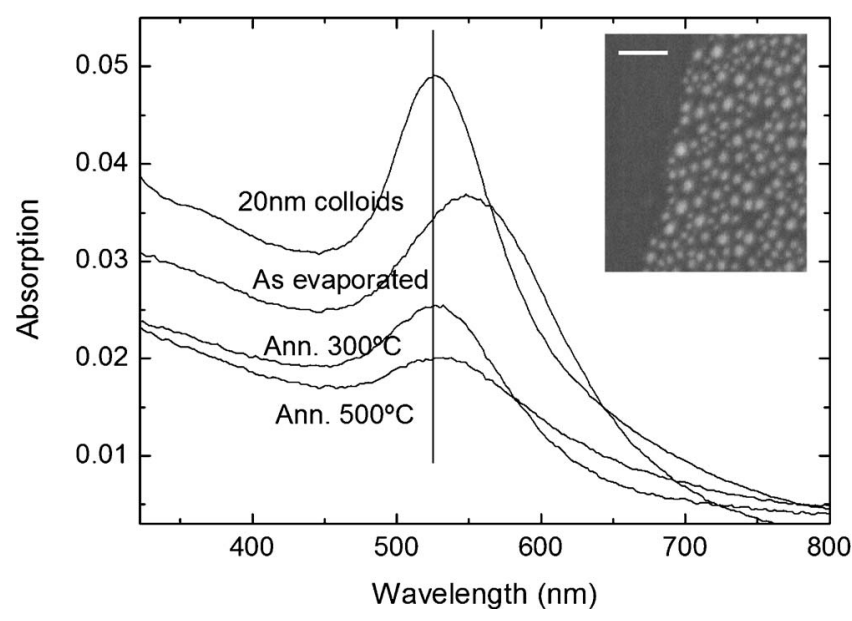

FIG. 1. Optical absorption spectra for 0.5-nm-thick Au layers on quartz. An absorption spectrum for Au colloids $20 \mathrm{~nm}$ in diameter is shown as reference. (Inset) SEM micrograph of a patterned $\mathrm{Au}$ layer on $\mathrm{SiO}_{2}$ annealed at $300{ }^{\circ} \mathrm{C}$, showing the bright contrast due to $\mathrm{Au}$ nanoparticles. Scale bar: $100 \mathrm{~nm}$.

Early models correlated the absorption resonance shift to the area fraction of the surface covered by metal nanoclusters ${ }^{65}$ and consistently predicted a blueshift when a thin film splits into isolated nanoparticles. Further studies, however, pointed out that quantitative predictions for the precise position of the resonant frequency and the width of the resonance peak are challenging, since they are functions of particle size, shape, and interaction effects among densely arrayed nanoparticles. ${ }^{63,66,67}$ From Fig. 1, we can infer that restructuring of the as-evaporated Au film already occurs at $300{ }^{\circ} \mathrm{C}$. This is a critical point, because a low, substratecompatible NW growth temperature would be less appealing if a high temperature annealing was required beforehand for effective catalyst preparation. Interestingly, annealing at $500{ }^{\circ} \mathrm{C}$ leads to a small redshift and broadening compared to the $300{ }^{\circ} \mathrm{C}$ sample. It is known that increasing the annealing temperature leads to sintering and coalescence of nanoparticles, resulting in larger particle size at the expense of particle density. ${ }^{63}$ Additional parameters can significantly affect the formation of efficient catalyst nanoparticles for carbon nanotube (CNT) or NW growth, such as annealing atmosphere ${ }^{68}$ roughness/morphology of the substrate, ${ }^{69}$ or plasma treatments with reactive gas species (see Sec. III B, Refs. 70 and 71).

\section{B. Catalytic CVD growth (type-I)}

$\mathrm{Au}$ has been widely used to promote CVD SiNW growth. ${ }^{24-27}$ Its popularity comes essentially from two merits: (a) it does not oxidize in air or oxygen-rich atmospheres, and (b) it forms a liquid $\mathrm{Au}-\mathrm{Si}$ eutectic at a relatively low temperature $\left(363{ }^{\circ} \mathrm{C}\right) .^{72}$ It is often assumed that, according to the vapor-liquid-solid (VLS) model, ${ }^{28,29} \mathrm{NW}$ formation occurs when a catalyst droplet becomes supersaturated with the NW precursor. This then precipitates from the solidliquid interface to form a crystalline wire or tube. ${ }^{28,29}$ The metal particle size determines the final diameter and is usually found at the tip of the NW. In principle, the lowest possible growth temperature allowed by the VLS is the melt- 
ing temperature of the catalyst particle. Accordingly, SiNWs growth in the $365-450{ }^{\circ} \mathrm{C}$ range is generally considered "low-temperature synthesis." point of $\mathrm{Si}-\mathrm{Au}$ eutectic nanoparticles may be lower than the value reported in bulk phase diagrams. It has been pointed out that size, precursor saturation, and substrate effects could significantly shift the catalyst melting temperature ${ }^{74,75}$ In fact, the VLS mechanism was invoked to explain NW growth for Si (Ref. 24) and Ge (Ref. 76) slightly below the $\mathrm{Au}-\mathrm{Si}$ or $\mathrm{Au}-\mathrm{Ge}$ eutectic temperature. ${ }^{24,76}$ On the other hand, there is considerable evidence that NW nucleation can also occur with a solid catalyst. ${ }^{31,32,77,78}$ Indeed, Ref. 31 showed that the growth of InAs NWs is hindered as soon as the temperature exceeds the predicted melting point of $\mathrm{Au}-$ In. Here we find a combination of growth parameters allowing SiNW synthesis at $300{ }^{\circ} \mathrm{C}$ both by CVD and PECVD. Since such low-temperature regime widens the available range of compatible substrates (e.g., plastic materials), we choose $300{ }^{\circ} \mathrm{C}$ as the growth temperature for our CVD experiments. A relatively low temperature can also minimize undesirable effects such as catalyst diffusion or migration during NW growth. ${ }^{60,79}$

For thermal CVD, pure $\mathrm{SiH}_{4}$ is used. Figures 2(a) and 2(b) show SiNWs grown with $\mathrm{SiH}_{4}$ pressures of 1 and 10 Torr, respectively. Straight and thin $(10-20 \mathrm{~nm})$ SiNWs arise from Au-coated areas, and their length and density increase with increasing $\mathrm{SiH}_{4}$ pressure. No wires are found for $\mathrm{SiH}_{4}$ pressures below 1 Torr, but only unshaped $\mathrm{Si}$ structures on the catalyst layer. At $600{ }^{\circ} \mathrm{C}$, however, SiNW growth was reported inside a transmission electron microscope for precursor gas pressures as low as $10^{-5}$ Torr. $^{79}$ This would suggest that temperature and pressure are critically related in promoting 1D crystallization during CVD growth of SiNWs. The reaction dynamics changes dramatically in the presence of a plasma. At 10 Torr no plasma is ignited. At 3 Torr [Fig. $2(\mathrm{c})$ ], with low plasma power $(10 \mathrm{~W})$, we observe relatively thick and tapered SiNWs $(100-300 \mathrm{~nm})$, up to tens of microns in length. Thus, for similar $\mathrm{SiH}_{4}$ pressures, a great enhancement of the Au-promoted elongation rate is observed for PECVD compared to thermal CVD.

Representative TEM micrographs of thermally grown SiNWs are shown in Figs. 3(a) and 3(b). Thermal CVD yields thin $(\sim 10 \mathrm{~nm})$ crystalline NWs uniform in diameter. The 1-2 nm amorphous shell, seen in Fig. 3(b), is attributed to native $\mathrm{Si}$ oxide formed during air exposure after deposition. ${ }^{27}$ Figure 3(c) shows the final section of a SiNW grown by PECVD. The Au catalyst particle is at the wire tip, as indicated by the arrow. The conical shape of the NW in Fig. 3(c) implies that when plasma is used we get an enhancement of radial deposition on the NW sidewalls, as well as of catalytic growth. In fact, a close inspection of Fig. 2(c) reveals that some superimposing NWs merge at crossing points. This is a consequence of radial growth for NWs that elongated initially from independent catalyst particles.

Figure 2 suggests that, to fabricate shorter and thinner NWs by PECVD, a smaller amount of $\mathrm{SiH}_{4}$ should be supplied during the process. This can be done both by decreasing the total pressure and by diluting the $\mathrm{SiH}_{4}$ precursor. Several groups reported thermal synthesis of SiNWs by us-
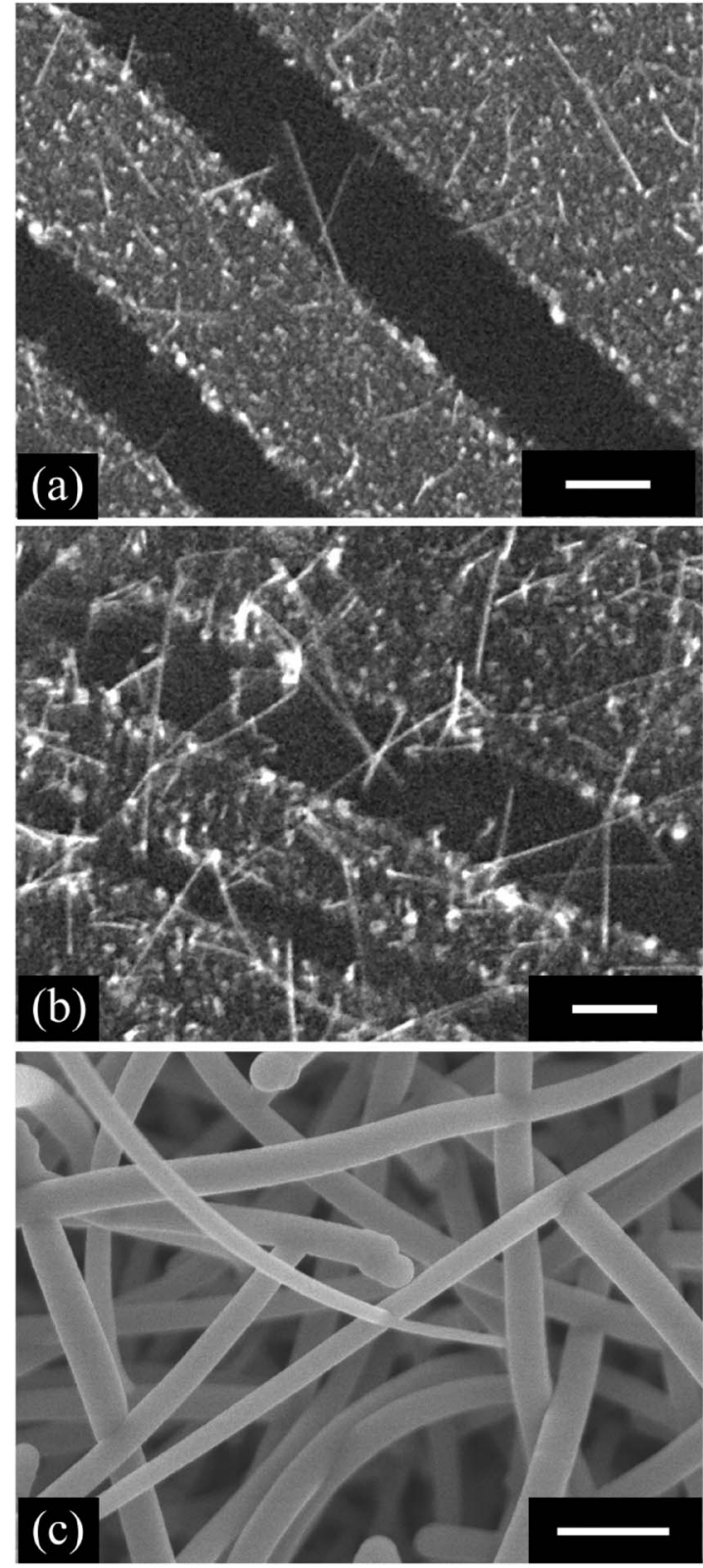

FIG. 2. [(a) and (b)] SiNWs grown by thermal CVD at $300{ }^{\circ} \mathrm{C}$ with $\mathrm{SiH}_{4}$ pressures of (a) 1 Torr and (b) 10 Torr. Straight and thin (10-20 nm) NWs arise from Au-coated patterned lines, and their yield increases with pressure. (c) Thick and tapered NWs (100-300 nm), tens of microns in length, fabricated with a $\mathrm{SiH}_{4}$ pressure of 1 Torr, but with the addition of a $10 \mathrm{~W}$ rf plasma. Scale bars: $500 \mathrm{~nm}$.

ing He-diluted and/or $\mathrm{H}_{2}$-diluted $\mathrm{SiH}_{4} \cdot{ }^{24,25,80}$ We selected $\mathrm{H}_{2}$ as a diluent, based on the speculation that $\mathrm{H}$-terminated $\mathrm{Si}$ surfaces may hinder the plasma-promoted radial growth rate. ${ }^{81}$ Figure 4 shows SiNWs grown by PECVD with different dilution ratios of $\mathrm{SiH}_{4}$ in $\mathrm{H}_{2}$. Here, the total pressure is constant at 200 mTorr. At this pressure pure thermal growth is ineffective, as explained above. When pure $\mathrm{SiH}_{4}$ is used at 200 mTorr [Fig. 4(a)], shorter wires $(4-8 \mu \mathrm{m})$ are produced compared to Fig. 2(c) (pure $\mathrm{SiH}_{4}, 3$ Torr). Dilution of $\mathrm{SiH}_{4}$ in $\mathrm{H}_{2}$ progressively makes the wires shorter and thinner [Figs. 4(b)-4(d)], but they still retain a conical shape in all cases. Hence, both longitudinal and radial growths always occur when a plasma is used [see Fig. 5(a)], though their 

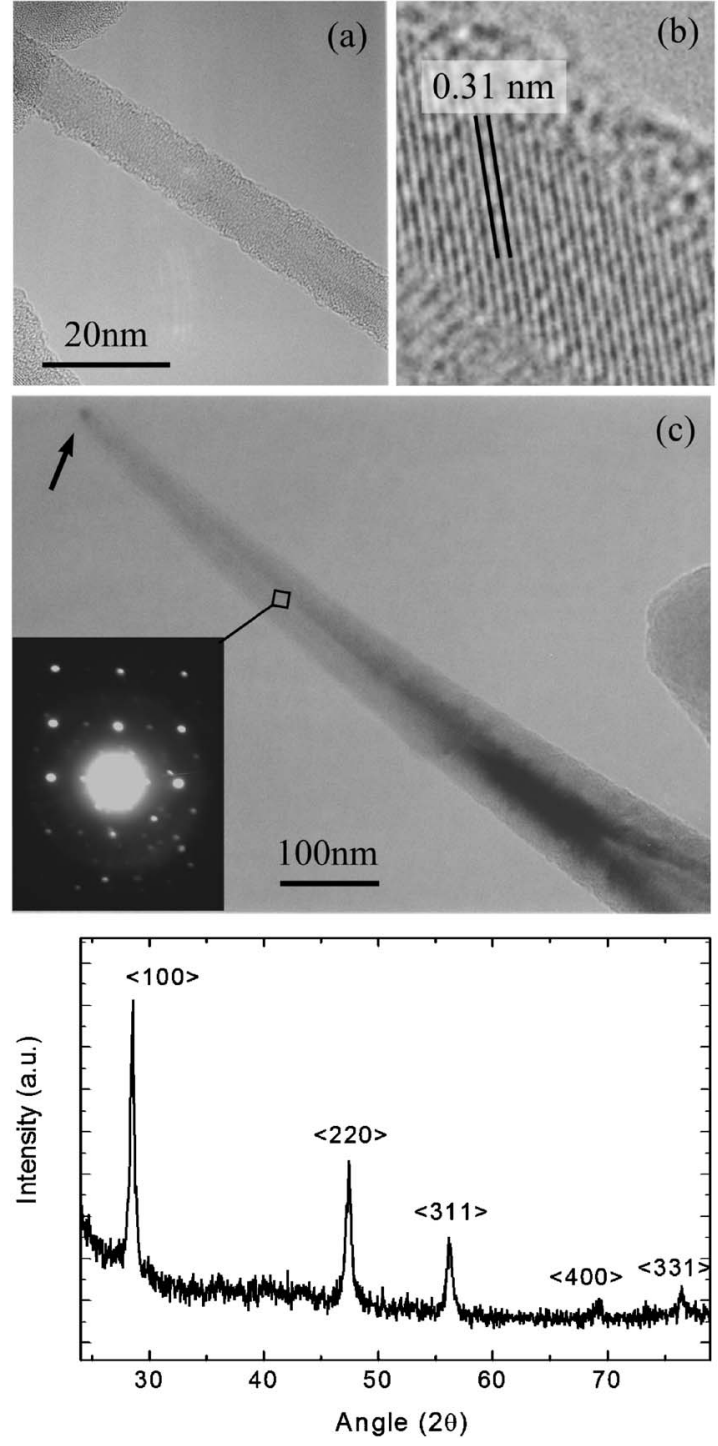

FIG. 3. [(a) and (b)] TEM micrographs of crystalline, thermally grown SiNWs, with a uniform diameter of about $10 \mathrm{~nm}$. The thin amorphous shell in (b) is attributed to native $\mathrm{Si}$ oxide formed during extended air exposure after deposition. (c) SiNC grown by PECVD. The Au seed particle is at the cone tip. (d) XRD $2 \theta$-scan of SiNCs grown on quartz, showing diffraction peaks for cubic silicon.

dependence on the dilution ratio is different. The average NC length and diameter (measured at the base of the cone profile) as a function of the $\mathrm{H}_{2}: \mathrm{SiH}_{4}$ dilution ratio are plotted in
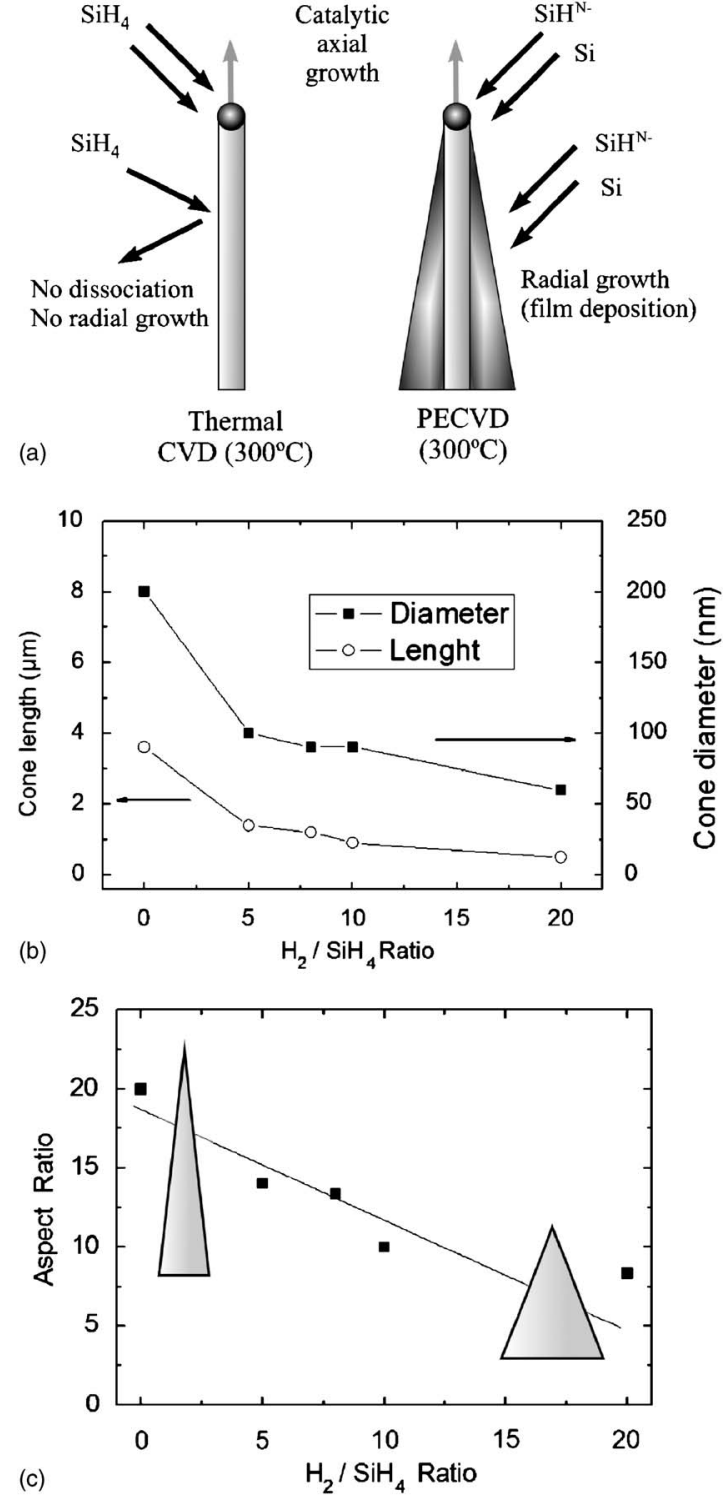

FIG. 5. (a) Scheme of thermal and plasma-enhanced CVD growth of SiNWs. A plasma provides active radicals that promote radial growth. (b) Average $\mathrm{NC}$ length and diameter as a function of $\mathrm{H}_{2}: \mathrm{SiH}_{4}$ dilution ratio. (c) The final $\mathrm{NC}$ aspect ratio (length/diameter) decreases linearly as $\mathrm{H}_{2}$ is added.

Fig. 5(b). We find that the final $\mathrm{NC}$ aspect ratio (length/ diameter) decreases linearly as $\mathrm{H}_{2}$ is added, indicating that the axial growth rate responds more rapidly to $\mathrm{H}_{2}$ [Fig. 5(c)].

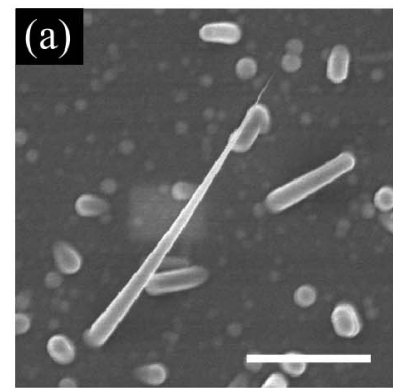

pure $\mathrm{SiH}_{4}$

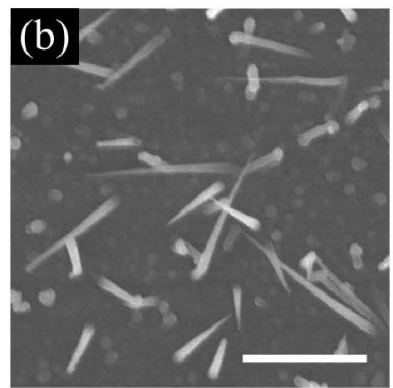

$5: 1$

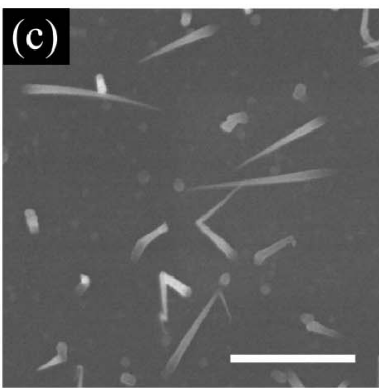

$10: 1$

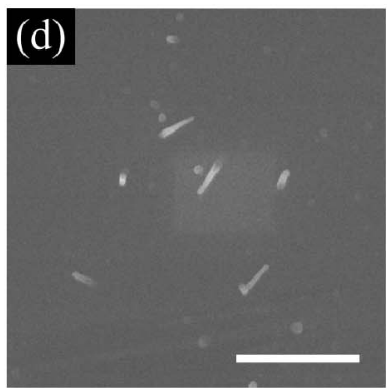

$20: 1$

FIG. 4. SiNCs grown by PECVD with different dilution ratios $\mathrm{H}_{2}: \mathrm{SiH}_{4}$. (a) $0: 1=$ pure $\mathrm{SiH}_{4}$, (b) 5:1, (c) 10:1, and (d) 20:1. The total pressure is kept constant to 200 mTorr. The maximum density of straight and sharp nanocones is found for dilution ratios between $5: 1$ and $10: 1$. Scale bars: $1 \mu \mathrm{m}$. 
Radial growth for Si and Ge NWs leading to conicalshaped nanostructures was previously demonstrated by thermal CVD using $\mathrm{SiH}_{4}$ and $\mathrm{GeH}_{4}$ as precursors. ${ }^{82,83}$ Since radial growth is not determined by the Au catalyst, the gas molecules must be thermally decomposed prior to incorporation. For GeNWs $300{ }^{\circ} \mathrm{C}$ was enough for $\mathrm{GeH}_{4}$ decomposition, ${ }^{83}$ while temperatures as high as $650{ }^{\circ} \mathrm{C}$ were needed to dissociate $\mathrm{SiH}_{4}{ }^{82}$ This is consistent with the higher dissociation energy of $\mathrm{SiH}_{4}$ compared to $\mathrm{GeH}_{4}{ }^{82-84}$ Here, we show that shape control of SiNCs can be obtained at $300{ }^{\circ} \mathrm{C}$ if a plasma is used to dissociate the precursor. Further, all the NCs presented here have a cubic-diamond crystal structure, as confirmed by XRD measurements in Fig. 3(d) (in contrast with the hexagonal diamond structure proposed in Ref. 82).

Figure 4 also shows a different density of NCs as a function of $\mathrm{H}_{2}$ concentration. Despite the higher growth rate, when using pure $\mathrm{SiH}_{4}$ [Fig. 4(a)] the NC density is relatively low. Moreover, many NCs are truncated and have no sharp tip, indicating that catalyst-driven axial elongation fails at the early stages of the process. By adding low concentrations of $\mathrm{H}_{2}$, the density of "fully formed" $\mathrm{NCs}$ is found to increase significantly. We then infer that the $\mathrm{H}_{2}$ plasma is beneficial to enhance catalyst activity during growth. However, an excessive amount of $\mathrm{H}_{2}$ (coupled with lower $\mathrm{SiH}_{4}$ partial pressures) eventually leads to a dominant etching effect suppressing Si deposition [Figs. 4(c) and 4(d)].

To further address this important point, we fix a welldefined synthesis protocol (total pressure of 200 mbars, $\mathrm{H}_{2}: \mathrm{SiH}_{4}$ dilution ratio $3: 1$, plasma $15 \mathrm{~W}$, growth time $10 \mathrm{~min}$ ) and assess the effect of $\mathrm{H}_{2}$ plasma applied before the NW synthesis. This allows us to investigate the effect of $\mathrm{H}_{2}$ plasma as a function of substrate preparation only. This is performed in situ at the chosen growth temperature for 3 min, immediately prior growth. The pretreatment plasma power is varied: $0 \mathrm{~W}$ [no pretreatment, Fig. 6(a)], $15 \mathrm{~W}$ [Fig. 6(b)], $30 \mathrm{~W}$ [Fig. 6(c)], and $100 \mathrm{~W}$ [Fig. 6(d)]. Figure 6 shows that a $30 \mathrm{~W} \mathrm{H}_{2}$ pre-plasma is strongly beneficial in activating the catalyst particles, compared to milder powers. However, if the $\mathrm{H}_{2}$ plasma becomes too aggressive (e.g., $100 \mathrm{~W})$, the Au nanoparticles are etched away almost entirely, and the final NW yield dramatically drops [Fig. 6(d)].

The physical effect of the $\mathrm{H}_{2}$ preplasma leading to an enhancement in NW growth is not fully understood. It may be due to further restructuring or cleaning of the catalyst particles (already formed at $300{ }^{\circ} \mathrm{C}$ ), to a microscopic reshaping of the substrate surface, more efficiently triggering initial NW nucleation, or a combination of these. ${ }^{70}$ It is noteworthy that thermal CVD of SiNWs also benefits from the pretreatment procedure. By using a $30 \mathrm{~W} \mathrm{H}_{2}$ preplasma, a SiNW density comparable to Fig. 2(b) (10 Torr, no pretreatment) is obtained for lower $\mathrm{SiH}_{4}$ pressures. Still, at $300{ }^{\circ} \mathrm{C}$, thermal SiNW nucleation is hardly seen below 1 Torr, irrespective of catalyst preparation.

\section{Catalytic growth by thermal evaporation (type-II)}

Substrate-bound SiNW growth can also be achieved by Au-assisted deposition in a vapor-transport reactor. Rather
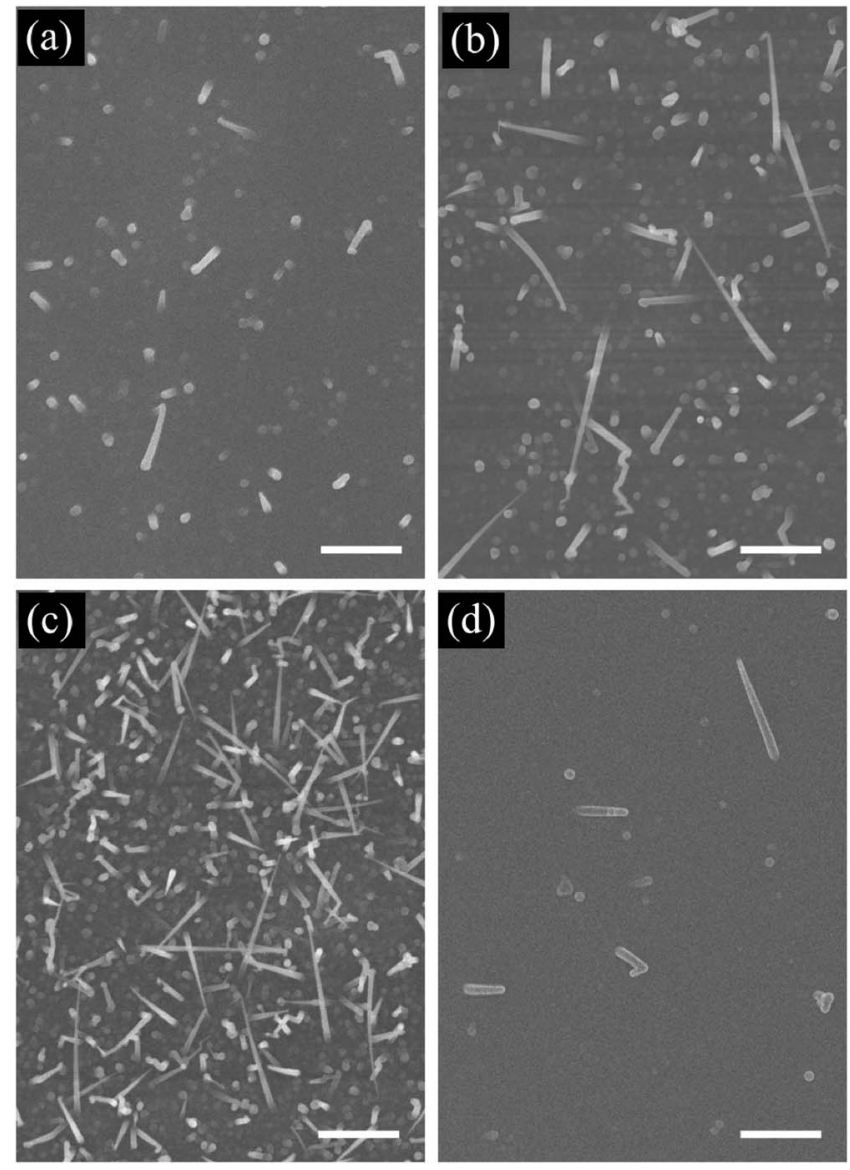

FIG. 6. Effect of $\mathrm{H}_{2}$-plasma substrate pretreatment for SiNWs nucleation. The growth conditions are kept fixed in all cases (total pressure 200 mbar, $\mathrm{H}_{2}: \mathrm{SiH}_{4}$ dilution ratio $3: 1$, plasma $15 \mathrm{~W}$, growth time $10 \mathrm{~min}$ ). The $\mathrm{H}_{2}$ pre-plasma step is performed in situ at the growth temperature for $3 \mathrm{~min}$, immediately prior growth. $\mathrm{H}_{2}$-plasma powers are (a) $0 \mathrm{~W}=$ no pretreatment, (b) $15 \mathrm{~W}$, (c) $30 \mathrm{~W}$, and (d) $100 \mathrm{~W}$. Scale bars: $1 \mu \mathrm{m}$

than using a molecular precursor gas, elemental $\mathrm{Si}$ is evaporated from the solid state and let diffuse in an inert Ar atmosphere. For these experiments, no appreciable differences are found for samples grown in the temperature range of $750-900{ }^{\circ} \mathrm{C}$.

Figure 7(a) shows SiNWs grown on Au-coated Si substrates by vapor transport, with the $\mathrm{Si}$ powder temperature set to $1250{ }^{\circ} \mathrm{C}$. The NWs are tens of microns in length, and their average diameter is between 20 and $30 \mathrm{~nm}$. As the powder temperature is lowered to $1150^{\circ} \mathrm{C}$, the local vapor pressure of elemental $\mathrm{Si}$ is also reduced and much shorter wires are found [Fig. 7(b)]. This shows the potential of controlling the SiNW growth rate by simply tuning the $\mathrm{Si}$ evaporation temperature within the $1150-1250{ }^{\circ} \mathrm{C}$ range. Although more elemental $\mathrm{Si}$ is available at $1250{ }^{\circ} \mathrm{C}$ also for radial growth, no tapering or sidewall overgrowth is observed for the wires in Fig. 7(a). This contrasts the trend observed for SiNCs grown by PECVD. We believe that, given the high substrate temperatures used here $\left(\sim 800^{\circ} \mathrm{C}\right)$, the $\mathrm{Si}$ vapor may desorb from the NW sidewalls, resulting in a negligible radial growth rate. Surface oxidation or passivation due to residual oxygen in the furnace tube may also be considered as a possible explanation. ${ }^{15,85}$ 


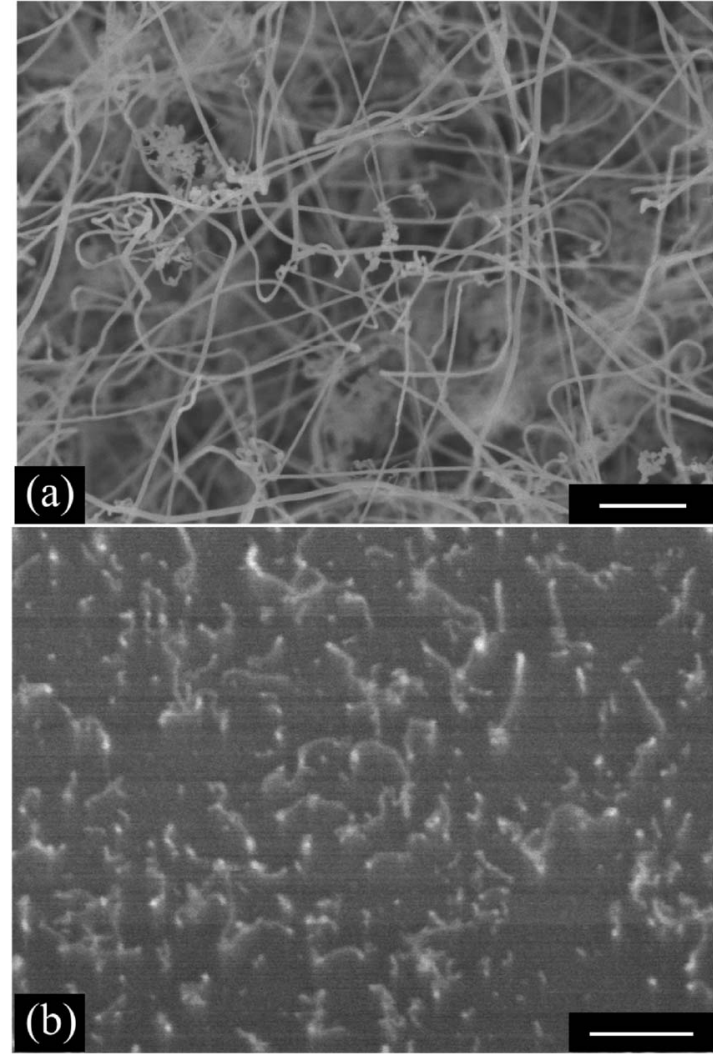

FIG. 7. SiNWs grown on Au-coated Si substrates at $\sim 800{ }^{\circ} \mathrm{C}$ by vapor transport. The Si powder temperature is (a) $1250{ }^{\circ} \mathrm{C}$ and (b) $1150{ }^{\circ} \mathrm{C}$. At $1250{ }^{\circ} \mathrm{C}$ the wires are tens of microns in length, with average diameter between 20 and $30 \mathrm{~nm}$. As the powder temperature is lowered to $1150{ }^{\circ} \mathrm{C}$, the local vapor pressure of elemental $\mathrm{Si}$ is also reduced and much shorter wires are found. Scale bars: $500 \mathrm{~nm}$.

A pronounced curliness is observed for the vaportransport NWs shown in Fig. 7. Compared to (PE)CVD ones (Figs. 2 and 4), the NWs in Fig. 7 look irregular, possibly a sign of a more disordered structure. However, if small sections of such NWs are analyzed by TEM [Figs. 8(a) and 8(b)], a single-crystal structure is observed both by highresolution lattice imaging [Fig. 8(c)] and selected area electron diffraction [Fig. 8(d)]. The curliness may therefore be attributed to wire fragmentation into several crystalline domains, possibly separated by amorphous or oxidized sections. No sharp kinks are observed, reflecting abrupt switches in the crystalline growth direction, unlike what previously reported in Ref. 27.

\section{Metal-free bulk production (type-III)}

For metal-free production of SiNWs we focus on the OAG method. ${ }^{15}$ By using Ar as carrier gas, Ref. 37 showed that SiNW yield strongly increases with the total pressure up to 400 mbars, and then remains roughly constant. We therefore restrict our experiments to Ar pressures above 400 mbars. We observe that the highest, milligram-scale NW deposition occurs in a very narrow region of the furnace tube (2-3 cm long), where the temperature is in the $900-950{ }^{\circ} \mathrm{C}$ range [Figs. 9(a) and 9(b)]. Outside this window, nucleation is negligible. After a growth run, the quartz support appears fully covered by a brownish, woolenlike product [Fig. 9(b)].
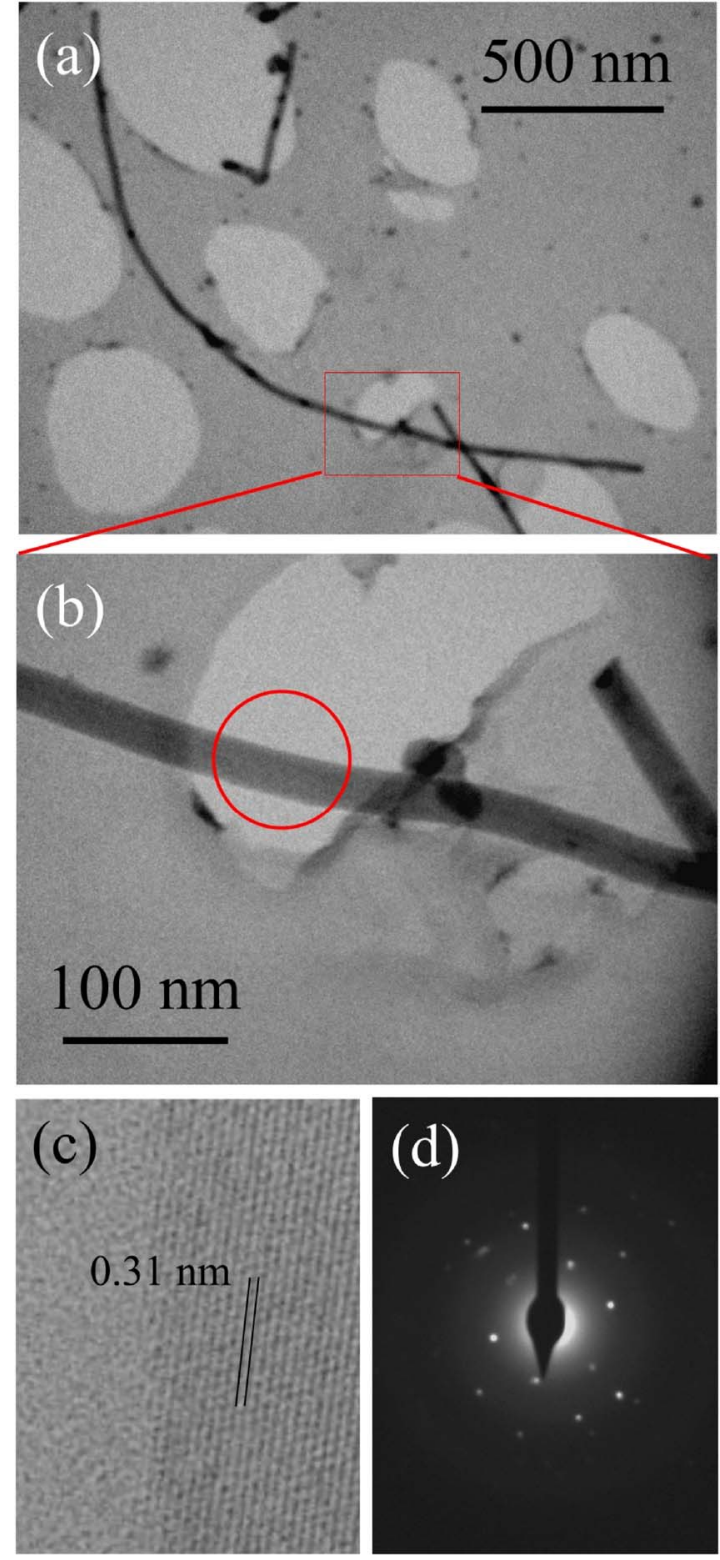

FIG. 8. (Color online) [(a) and (b)] Bright-field TEM micrographs of type-II SiNWs. The image in (b) is an enlargement of the boxed area in (a). Locally, a single-crystal structure is observed both by (c) high-resolution lattice imaging and (d) selected-area electron diffraction. The (c) high-resolution picture and the (d) diffraction pattern are taken on the NW section encircled in (b).

Total average yields per run consist in $2-5 \mathrm{mg}$ of SiNW bundles [Figs. 9(b) and 9(c)], as weighted using a microbalance.

Dispersion and processing of as-grown NW bundles are easier if no purification of the raw material is required. Thus, oxide-assisted SiNWs grown without any metal catalyst have the greatest potential. However, morphology and shape uniformity are as important as their chemical purity. Figures 9(d) and 9(e) show the representative SEM micrographs of dispersed SiNWs grown with total Ar pressures of 400 and 800 mbars, respectively. A major difference in morphology is evident. Pinlike nanochains are found for the 400 mbars run, while uniform wires become dominant as the pressure is increased to 800 mbars. In agreement with previous 

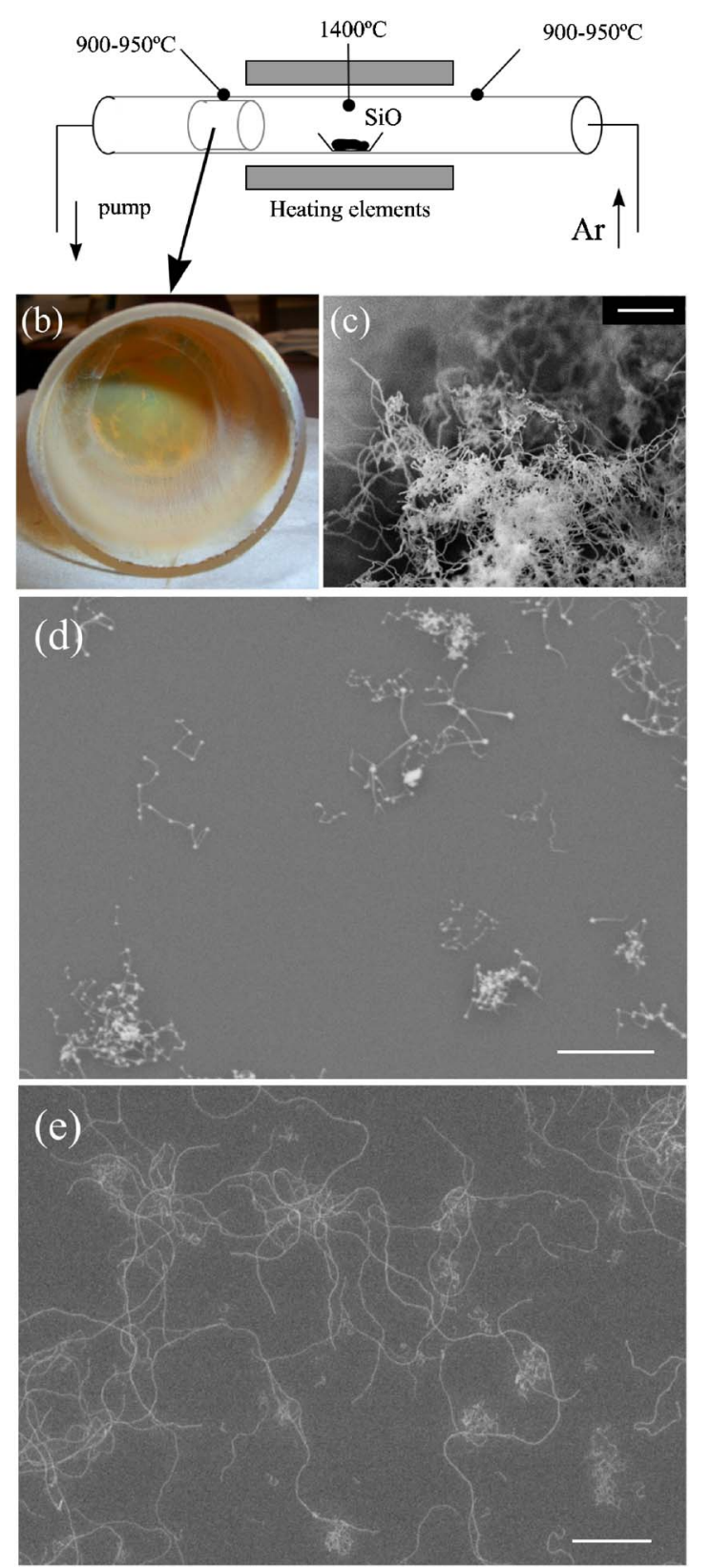

FIG. 9. (Color online) (a) Scheme of the furnace deposition setup. (b) Bulk production of SiNWs. The quartz support is fully covered by brownish, woollen-like SiNW bundles. (c) SEM image of raw SiNWs bundles as collected from the quartz support. [(d) and (e)] SEM micrographs of oxideassisted SiNWs grown at (d) 400 mbars, and (e) 800 mbars and dispersed on Si chips. Pinlike nanochain shapes are mainly found in (a), while uniform wires become dominant as the pressure is increased to 800 mbars (b). Scale bars: $1 \mu \mathrm{m}$

literature, ${ }^{37}$ the total yield remains roughly constant above 400 mbars. We therefore conclude that the process pressure is a key parameter to promote a uniform NW morphology.

Pin-like structures or nanochains consist of crystalline $\mathrm{Si}$ spheres connected by $\mathrm{SiO}_{2}$ bridges of variable length and thickness. ${ }^{41,43,44}$ Figure 10(a) shows a bright-field TEM micrograph of a Si nanochain grown at 400 mbars. The corresponding energy-filtered TEM oxygen map shown in Fig. 10(b) and the high-resolution transmission electron microscopy (HRTEM) micrograph in Fig. 10(c) confirm previous observations. $^{41,43}$ The ball-to-ball separation in such

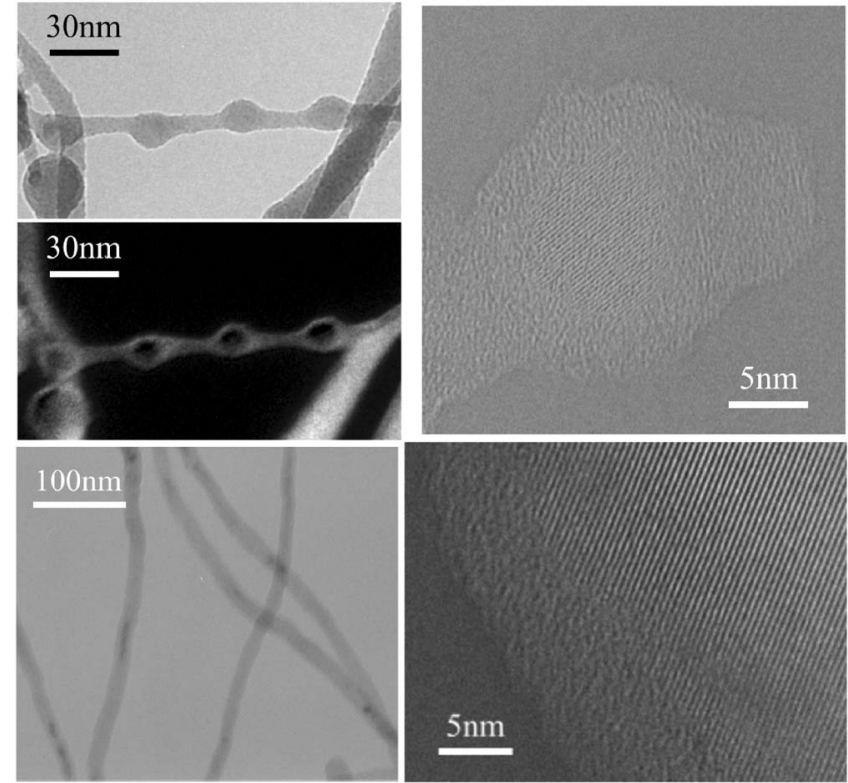

FIG. 10. (a) Bright-field TEM micrograph of a Si nanochain, and (b) the corresponding energy-filtered TEM oxygen map. (c) HRTEM of a single $\mathrm{Si}$ nanosphere confirming its crystalline nature. (d) Bright-field TEM micrograph of oxide-assisted, uniform SiNWs. (e) HR lattice imaging of a NW presented in (d), showing a Si crystalline core surrounded by a 6-nm-thick amorphous shell.

nanochains varies from $20 \mathrm{~nm}$ [as in Fig. 10(a)] to several hundreds nanometers [see Fig. 9(c)] and is inhomogeneous and hardly reproducible at 400 mbars. Figure 10(d) shows a bright-field TEM micrograph of SiNWs grown at 800 mbar. HR lattice imaging on such NWs [Fig. 10(e)] indicates a Si crystalline core surrounded by an oxide shell, much thicker than the native oxide thickness $(\sim 1-2 \mathrm{~nm})$ observed for CVD SiNWs. A small fraction of nanochains or, more often, NWs with varying diameter is sometimes detected at 800 mbars. In this case, however, the ball-to-ball distance does not exceed 2-3 nm. Oxide bridges of such a short length may behave as efficient tunneling barriers between the crystalline Si nanospheres, and allow detection of single electron charging effects up to room temperature. ${ }^{44}$

Several aspects of the oxide-assisted growth model are still debated. ${ }^{43,86-89}$ However, a possible explanation of the pressure-dependent shape control may be inferred. Reference 43 proposed the formation of nanochains as consequence of in situ partial oxidation of the as-synthesized NWs (possibly due to residual oxygen). Since the oxidation rate increases with temperature, this explains the observation that pinlike structures are formed in a hotter region compared to NWs. ${ }^{43}$ Reference 86 also showed that oscillations in the Ar pressure during growth lead to nanochains of controllable morphology. However, it did not explain if such a modulation effect occurs synchronously with NW growth or happens postnucleation.

In vapor transport, the material evaporating from the boat (furnace center, $1400{ }^{\circ} \mathrm{C}$ ) is assumed to drift downstream carried by the Ar flow and to condense on the tube walls as soon as the temperature falls within the nucleation range $\left(900-950{ }^{\circ} \mathrm{C}\right) .{ }^{15,37}$ In our case, however, a lower yield of SiNWs is also found upstream the $\mathrm{SiO}$ boat, in the up- 
stream $900-950{ }^{\circ} \mathrm{C}$ region of the tube [see Fig. 9(a)]. This is not entirely surprising, since the vapor stream inside a several-centimeter-wide furnace tube is mainly due to diffusive transport, while the kinetic contribution due to the carrier gas (at 50-100 SCCM) is less important or even negligible, as we have shown in Ref. 45. Hence, since vapor transport is diffusion driven, oxygen diffusion can also be suppressed if the total Ar pressure is increased. This could explain the negligible oxidation rate we reproducibly achieve at 800 mbars.

\section{NANOWIRE DISPERSION}

Ongoing research suggests that polymer/CNT composites may exhibit unique characteristics in terms of mechanical $^{90}$ and optical ${ }^{91,92}$ properties. Hence, we investigate the dispersion of SiNWs in various organic solvents [ethanol, isopropyl alcohol (IPA), water, chloroform, toluene, dimethylformamide (DMF), and xylene] with the aim of forming polymer/SiNW composites.

For dispersion studies we use type-III SiNWs, since the OAG method gives the highest yield. Achieving effective dispersion of raw bundles is not immediate though, as SiNWs tend to form large aggregates. To achieve this, we use ultrasonication. We find that typical ultrasonic baths are capable of dispersing SiNWs, but an efficient debundling requires up to several hours. As an alternative, we obtain effective and rapid dispersion by means of high power sonication (e.g., tip sonication). This method, however, delivers much shorter wires because of fragmentation. We thus use a compromise process where SiNW bundles are inserted in a cuvette containing the solvent, and then placed in a $200 \mathrm{~W}$, $20 \mathrm{kHz}$ sonication bath (Bioruptor, Diagenode). Here, sonic waves emanate from the base of the water bath, and are reflected by a metal tip inserted in the cuvette. ${ }^{93}$ Sonic waves are both concentrated and distributed within the cuvette without being localized, as in the case of a sonication tip, where the sonic waves are solely distributed from the base of the tip [see Fig. 11(a)].

There is no mechanical effect on the crystalline quality of the wires due to sonication. High-resolution TEM and XRD do not indicate a significant increase of defects or disorder in dispersed NWs. The main consequence of high power sonication is to break long NWs into shorter fragments, though their single-crystal nature is maintained.

Our experiments indicate that IPA allows solution processing of SiNWs without the need of a surfactant. Following sonication, our IPA suspensions (up to $0.1 \mathrm{~g} / \mathrm{l}$ ) are stable for several days and are a consistent light yellow, Fig. 11(b). We did not achieve dispersion in toluene, xylene, and chloroform, where precipitation of SiNWs is observed, Fig. 11(c). It is well known that the solubility of solution-grown nanocrystals depends on a proper combination between polar/nonpolar solvents and hydrophobic/hydrophilic surfaces. ${ }^{94}$ Similarly, the hydrophilic $\mathrm{SiO}_{2}$ shell surrounding the wires triggers an easy dispersion of SiNWs in polar solvents and causes precipitation in nonpolar ones.

Dispersing semiconducting polymers and SiNWs in the same solvent facilitates the formation of mixtures. Contrary
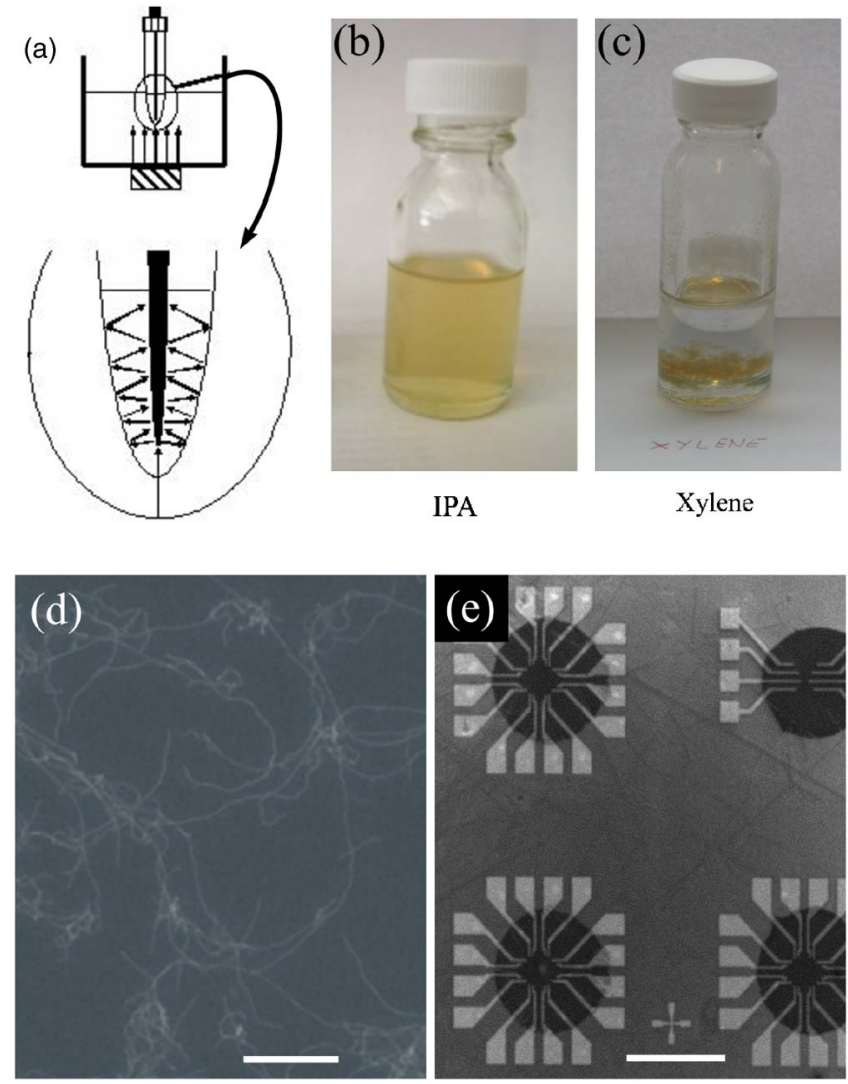

FIG. 11. (Color online) (a) Scheme of the sonicator operation principle. Samples are contained in a cuvette that is placed in a water bath. Here, sonic waves emanate from the base of the water bath, and are reflected by a tip inserted in the cuvette containing the solution of SiNWs. ${ }^{93}$ (b) stable SiNW dispersion in IPA or NMP. (c) SiNW precipitation when xylene is used as solvent. (d) SEM micrograph of ink-jetted SiNWs using the solution shown in (b). Scale bar: $1 \mu \mathrm{m}$. (e) 500- $\mu \mathrm{m}$-wide drops of PQT-SiNW composite after ink jetting onto predefined contact arrays. Scale bar: $500 \mu \mathrm{m}$.

to what is seen above for SiNWs, however, semiconducting organic molecules [e.g., poly-3-hexylthiophene (P3HT), poly(9,9-dioctylfluorene-co-bithiophene) (F8T2), poly(3,3dialkyl-quaterthiophene) (PQT)] tend to be far more easily dissolved in nonpolar solvents, such as xylene. Attempts to promote dispersion of SiNWs in xylene using surfactants such as octadecylamine (which was used in Ref. 46 in combination with isooctane and IPA) did not improve the results. Still, we found that $N$-methyl-2-pyrrolidone (NMP), a dipolar aprotic solvent, behaves as a good compromise solvent in which stable solutions of both SiNWs (with concentrations similar to that of IPA solutions) and organic semiconductors (PQT, for instance) can be formed. This provides a promising approach to achieve high-concentration NW/polymer composites. As a further step, we demonstrated the feasibility of ink-jet printing of nanostructured materials [such as SiNWs, Figs. 11(d) and 11(e)] for a variety of applications, ${ }^{95}$ which opens opportunities for inexpensive large area fabrication of plastic electronics.

\section{ELECTRICAL TRANSPORT}

Figure 12 compares representative transfer curves $\left(I_{\mathrm{DS}}-V_{\mathrm{GS}}\right)$ for SiNWs grown by the different methods described in Sec. III. The devices are interdigitated multiple- 

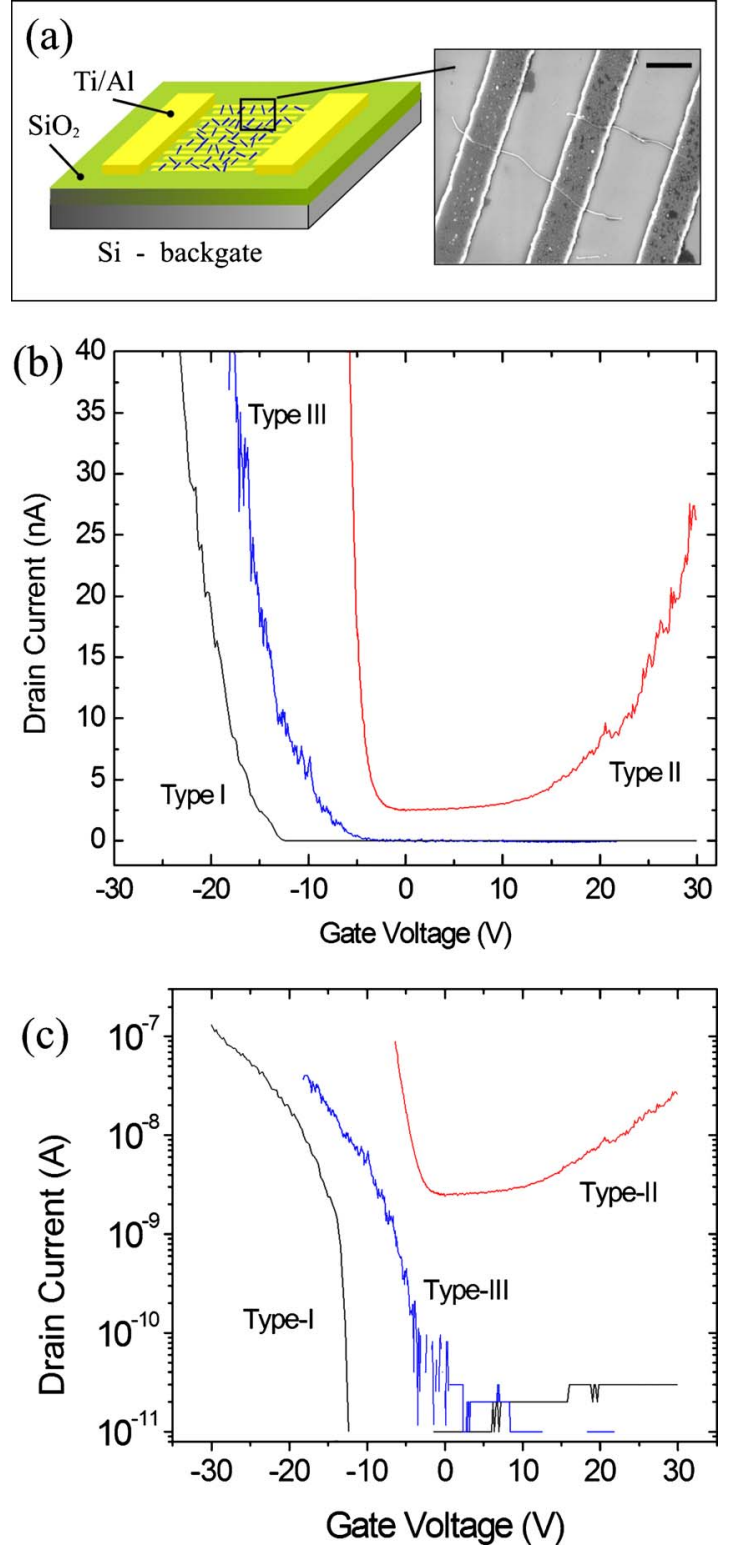

FIG. 12. (Color online) (a) Scheme and SEM micrograph of interdigitated multiple-channel planar SiNW FETs. Scalebar: $1 \mu \mathrm{m}$. (b) Representative transfer curves $\left(I_{\mathrm{DS}}-V_{\mathrm{GS}}\right)$ for SiNWs grown by different methods. Curves correspond to devices with 7, 24, and 10 SiNWs (for types I, II, and III, respectively). (c) Transfer curves for SiNWs plotted on a vertical log scale, showing the maximum/minimum on/off currents.

channel planar FETs, as illustrated in Fig. 12(a). Compared to single-NW FETs, our devices are more representative of a given growth technique, since a large statistics integrated over several NWs is considered. A qualitative analysis of Fig. 12(b) shows that all our SiNW FETs switch on for negative gate voltages, which is an indication of hole-dominated transport. The normalized transconductance can be extracted from the slope $d I_{\mathrm{DS}} / d V_{\mathrm{GS}}$ in the left part of the curve divided by the effective channel width $N d$, where $d$ is the average wire diameter and $N$ is the number of wires contacted within the same device. ${ }^{8}$ Curves in Fig. 12(b) correspond to devices with 7, 24, and 10 SiNWs (for types I, II, and III, respectively). These give very similar values $\left(28-40 \mathrm{nS} \mu \mathrm{m}^{-1}\right.$ ) for the normalized transconductance, which turns out to be sensibly lower than other reports available in the literature. ${ }^{8} \mathrm{We}$

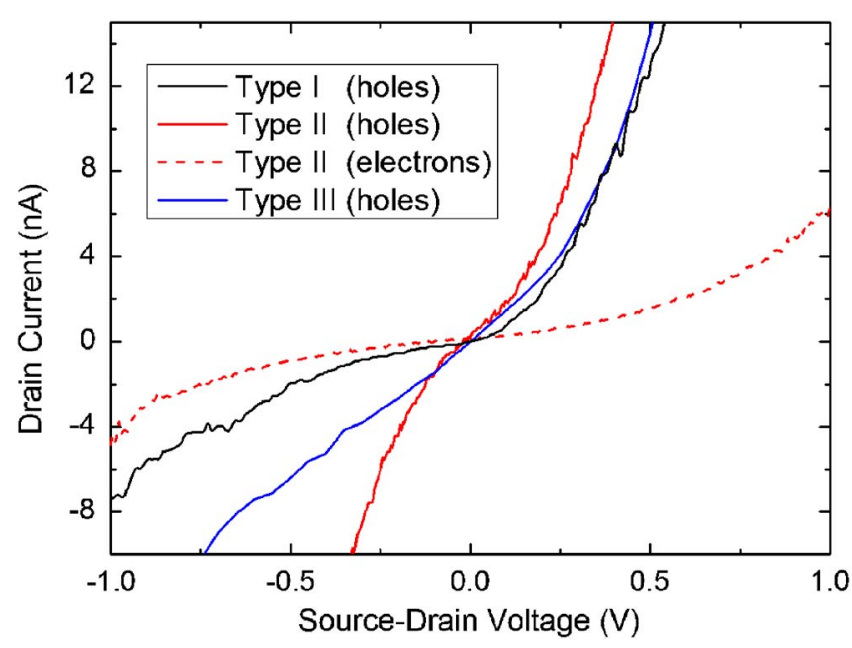

FIG. 13. (Color online) Output curves $\left(I_{\mathrm{DS}}-V_{\mathrm{SD}}\right)$, corresponding to devices presented in Fig. 12, measured for gate voltages corresponding to the on states. For ambipolar SiNWs, we also show the output curve for the on state due to electron population.

also observe that type-II SiNWs show ambipolar behavior, i.e., electron injection occurs for positive gate voltages. The current due to electrons, however, always shows a lower subthreshold slope compared to holes [see also Fig. 12(c), where transfer curves are plotted on a log scale]. The ambipolar effect is reproducibly observed for type-II SiNWs, while it never occurs for type I or type III. We note from Figs. 12(b) and 12(c) that our ambipolar devices cannot be completely turned off, but a residual current is detected at room temperature for intermediate gate voltages.

Figure 13 plots the corresponding output curves $\left(I_{\mathrm{DS}}-V_{\mathrm{SD}}\right)$ for all types of SiNWs, measured for gate voltages corresponding to the on states. For ambipolar SiNWs, we also show the output curve for the on state due to electron population (i.e., for high positive gate voltages). In all cases, a clear nonlinearity is observed in the output curves, indicating that the contacts between NWs and metal leads are not Ohmic but rather a Schottky barrier is present. ${ }^{96}$ Typical total device resistances in the on state are in the 1-100 $\mathrm{M} \Omega$ range. We note, however, that the output curves are often non-symmetric when reversing the applied bias. This effect is amplified if the number of NWs within a single device is reduced. We conclude that contacts are in general nonequivalent and a wide distribution of contact resistances may exist for a single fabrication process, leading to a situation where only a few wires are dominating the electrical transport for an individual device. This can mislead the estimation of normalized FET parameters.

A direct comparison of the absolute threshold voltages measured for different devices is quite challenging because of hysteresis effects. Hysteresis in $I_{\mathrm{DS}}-V_{\mathrm{GS}}$ measurements for CNT- or NW-based FETs has been widely reported, and mainly attributed to charge trapping in the surface states of $\mathrm{SiO}_{2}{ }^{8,41,61,97}$ Such charges may generate electric fields of opposite sign superimposed to the applied gate voltage. As an example, in Fig. 14 we show $I_{\mathrm{DS}}-V_{\mathrm{GS}}$ curves for type-I NWs for different gate sweeping ranges. If two curves are consecutively collected by sweeping the gate voltage from -10 to $10 \mathrm{~V}$ and vice versa (solid lines), only a small hys- 


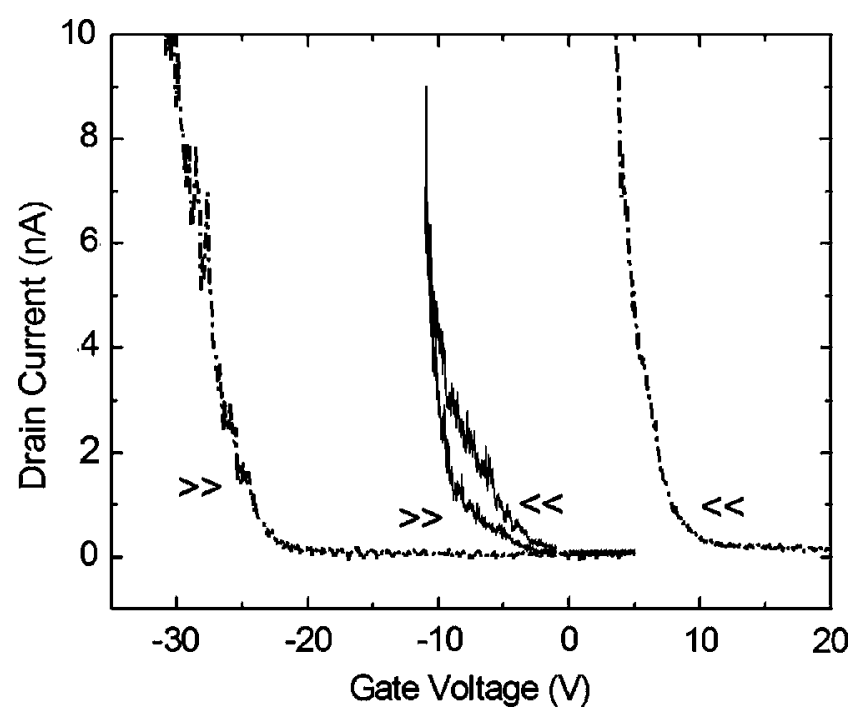

FIG. 14. Hysteresis effects for $I_{\mathrm{DS}}-V_{\mathrm{GS}}$ transfer curves. Type-I NWs are considered here as an example but a similar behavior is found in all cases. If two curves are consecutively collected by sweeping the gate voltage from -10 to $10 \mathrm{~V}$ and vice versa (solid lines, the arrows indicate the sweeping direction), only a small hysteresis is seen. If the sweeping range is extended from -30 to $30 \mathrm{~V}$, a large shift, up to $35 \mathrm{~V}$, is observed when reversing the scan (dotted lines).

teresis is seen. However, if the sweeping range is extended from -30 to $30 \mathrm{~V}$, a big shift, up to $35 \mathrm{~V}$, is observed when reversing the scan (dotted lines). This shows that the trapped charge screening is proportional to the initial gate field applied. Such memory effect is stable for several hours in air and at room temperature, and no quick discharge is possible to reproduce the original measurement conditions.

Because of hysteresis, we cannot use the absolute threshold voltage from Figs. 12(b) and 12(c) as a representative parameter. However, further insights can be extracted for type-II ambipolar devices by looking at the residual current in the "off" plateau and the relative separation between hole and electron threshold voltages. In Fig. 15(a) we show the temperature dependence of transfer curves for type-II SiNWs. For this measurement set, we always sweep the gate voltage from $30 \mathrm{~V}$ toward negative voltages (except for the $4 \mathrm{~K}$ curve, which starts from $40 \mathrm{~V}$ and is collected separately in a liquid-He cryostat). This results in a right shift for all curves compared to Fig. 12(b). Three distinct regimes can be isolated for each curve: a hole-injection branch on the left, a flat plateau in the middle, and an electron-injection branch on the right. At $4 \mathrm{~K}$, no current is detected in the central region, whereas the thresholds for hole and electron injection are up to $30 \mathrm{~V}$ apart. When the temperature increases to room temperature and above, two simultaneous effects are seen. An increasing plateau current is measured [as indicated by the arrow in Fig. 15(a)], while the relative distance between electron and hole threshold voltages progressively shrinks.

In the plateau region, the semiconductor bands are bent by the gate voltage in such a way that no electron or hole tunneling is possible [Fig. 15(a), central inset]. Hence, we attribute the residual off current in this regime to thermionic emission (independent of $V_{\mathrm{GS}}$ ). When the downward (upward) band bending becomes sharp enough, it is possible for

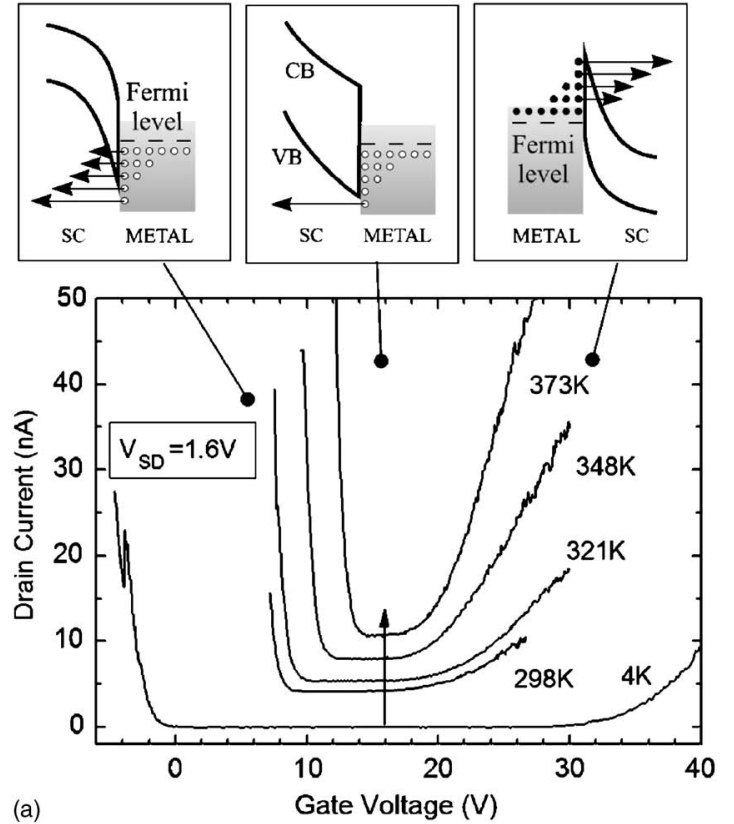

(a)

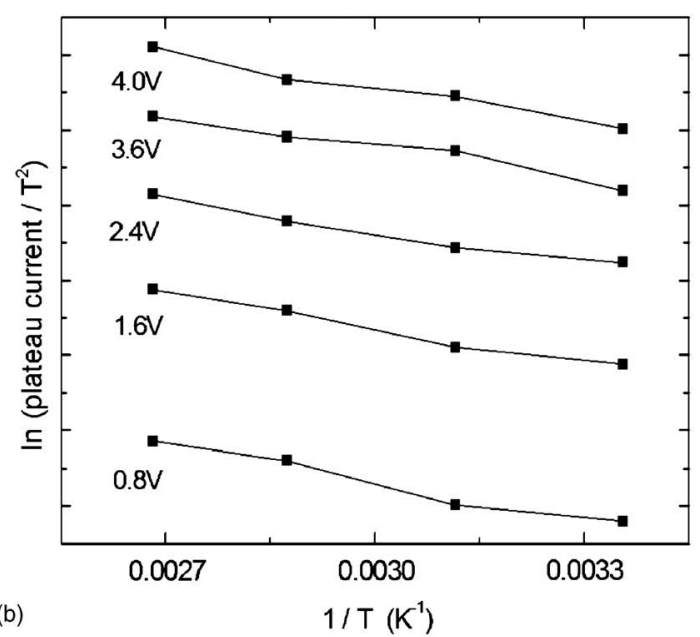

FIG. 15. Temperature dependence of electrical transport for type-II SiNWs. Three distinct regimes can be isolated for each curve, corresponding to the band diagrams schematically shown in the insets: a hole-injection branch on the left part, a flat plateau in the middle, and an electron-injection branch on the right. When temperature is raised, an increasing plateau current is measured (arrow), while the relative distance between electron and hole threshold voltages progressively shrinks. (b) Arrhenius plots for the residual plateau currents on type-II SiNW transfer curves. The source-drain voltage is reported for each set of measurements.

electrons (holes) to tunnel from the metal to the semiconductor conduction (valence) band. The higher the temperature, more electrons (holes) are populating states above (below) the Fermi level, according to the Boltzmann distribution. These hot carriers see a thinner tunneling barrier and can therefore be injected for smaller gate voltages [left and right insets in Fig. 15(a)]. Such thermal-assisted tunneling process is responsible for the "curve folding" observed in Fig. 15(a).

For fixed $V_{\mathrm{DS}}$, the plateau current due to thermal carriers is given by the Richardson-Dushman equation: ${ }^{98}$

$$
I \sim T^{2} e^{-\Phi / K T},
$$

where $\Phi$ is the barrier height and $K$ is the Boltzmann constant. In Fig. 15(b) we plot the measured values of $\ln \left(I / T^{2}\right)$ 
as a function of $1 / T$, in order to estimate the barrier height. This temperature dependence was measured for several $V_{\mathrm{DS}}$ $(0.8-4 \mathrm{~V})$, and a very similar slope was extracted in all cases. By combining the whole data set, we obtain a maximum activation energy of $0.08 \mathrm{eV}(0.06 \pm 0.02)$. Since hole injection appears most favorable and leads to lower device resistances (see Figs. 12 and 13), this value reflects the SiNW valence band offset with respect to the Fermi level of the metal.

It has been pointed out that, for nominally undoped SiNWs, the valence band is pinned to the Fermi level of the metal contacts, resulting in $p$-type semiconducting behavior. ${ }^{57,61,96}$ This is not surprising, since interfacial states in many metal-semiconductor junctions tend to generate an offset between valence band and Fermi level which is roughly $1 / 3$ of the semiconductor band gap. ${ }^{99,100}$ Yet, measured $\Phi$ is lower than that reported in previous experiments and theoretical predictions. ${ }^{57,96,99-101}$ Further investigations on the nanoscopic nature of the metal-NW contacts are needed in order to clarify this discrepancy.

For type-III SiNWs, Ref. 41 attributed the observed $p$-type behavior to $\mathrm{B}$ incorporation during growth. For the same type of wires, however, we measure a similar curve despite the absence of dopants [Fig. 12(b)]. For type-I SiNWs, Ref. 57 reported a nominally intrinsic NW device with almost ideal $\mathrm{Al}$ Ohmic contacts, though inferring the presence of a small Schottky barrier compared to heavily doped NWs. It is generally hard to quantify precisely low doping concentrations in SiNWs and the resulting band alignment, unless ambipolar devices are considered (see Ref. 62 for an extensive comparison).

Our study aims to identify general differences in the electrical response due to different growth protocols. Therefore, our devices are not annealed after contact fabrication (unlike most previous works ${ }^{3,56,60-62}$ ). This minimizes effects such as catalyst diffusion, ${ }^{60}$ which could alter the comparison between wires grown by different processes. Type-II wires could have some contamination (possibly due to background doping) due to low-vacuum synthesis environment combined with the possible diffusion of the Au catalyst at the high growth temperatures used $\left(\sim 800^{\circ} \mathrm{C}\right) .{ }^{60}$ Since ambipolar behavior of NWs is generally regarded as a fingerprint of intrinsic material, ${ }^{18,102}$ we deduce that no detrimental effect is introduced by the type-II growth procedure compared to types I and III. Indeed, it remains an open question why ambipolar behavior is not seen for type-I or type-III NWs. Despite this discrepancy, however, in all cases device performance seems mainly dominated by the metal contacts, irrespective of how the NW active channels are fabricated or assembled.

\section{CONCLUSION}

We investigated and compared multiple routes to SiNW synthesis. As a function of the selected deposition technique, we achieved different yields, selective Au-catalyzed growth, bulk catalyst-free production, different nanocrystal morphologies, and relatively high or low nucleation temperatures. For each synthesis protocol, we highlighted the experi- mental parameters leading to morphology control. Concentrated and stable dispersions of SiNWs were obtained in solvents compatible with semiconducting organic polymers. Similar electrical properties are measured for SiNWs grown by different methods. All the considered FETs fabricated from intrinsic SiNWs show a preferential $p$-type behavior with comparable performance. In addition, devices based on Au-assisted SiNWs grown by thermal evaporation of Si powders (type II) are ambipolar. This indicates that no detrimental effects are introduced by using a metal catalyst, nor a low-vacuum furnace tube as deposition reactor.

\section{ACKNOWLEDGMENTS}

We thank L. Businaro, F. Romanato, and M. Lazzarino for support in e-beam and x-Ray lithography at LILIT beamline (Elettra-Trieste). We also thank R. E. Dunin-Borkowski for assistance in EFTEM mapping, P. Migliorato, M. Shaffer, and Z. A. K. Durrani for useful discussions. We acknowledge funding from the EU project CANAPE, Advance Nanotech, Peterhouse, Pembroke College, EPSRC, The Royal Society, The Leverhulme Trust, and the Ministry of Information and Communication, Republic of Korea (Project No. A11000602-0101).

${ }^{1}$ Y.-J. Doh, J. A. van Dam, A. L. Roest, E. P. A. M. Bakkers, L. P. Kouwenhoven, and S. De Franceschi, Science 309, 272 (2005).

${ }^{2}$ S. Jin, D. Whang, M. C. McAlpine, R. S. Friedman, Y. Wu, and C. M. Lieber, Nano Lett. 4, 915 (2004).

${ }^{3}$ M. C. McAlpine, R. S. Friedman, S. Jin, K. H. Lin, W. U. Wang, and C. M. Lieber, Nano Lett. 3, 1531 (2003).

${ }^{4}$ Y. Huang, X. Duan, and C. M. Lieber, Small 1, 142 (2005).

${ }^{5}$ C. Thelander, H. A. Nilsson, L. E. Jensen, and L. Samuelson, Nano Lett. 5, 635 (2005).

${ }^{6}$ I. Gur, N. A. Fromer, M. L. Geier, and A. P. Alivisatos, Science 310, 462 (2005).

${ }^{7}$ M. Law, L. E. Greene, J. C. Johnson, R. Saykally, and P. Yang, Nat. Mater. 4, 455 (2005).

${ }^{8}$ X. Duan, C. Niu, V. Sahi, J. Chen, J. W. Parce, S. Empedocles, and J. L. Goldman, Nature (London) 425, 274 (2003).

${ }^{9}$ Y. Huang, X. Duan, Y. Cui, L. J. Lauhon, K.-H. Kim, and C. M. Lieber, Science 294, 1313 (2001).

${ }^{10}$ Z. Zhong, D. Wang, Y. Cui, M. W. Bockrath, and C. M. Lieber, Science 302, 1377 (2003).

${ }^{11}$ S. Piscanec, M. Cantoro, A. C. Ferrari, A. Zapien, Y. Lifshitz, S. T. Lee, S. Hofmann, and J. Robertson, Phys. Rev. B 68, 241312(R) (2003).

${ }^{12}$ H. Scheel, S. Reich, A. C. Ferrari, M. Cantoro, A. Colli, and C. Thomsen, Appl. Phys. Lett. 88, 233114 (2006).

${ }^{13}$ C. B. Murray, C. R. Kagan, and M. G. Bawendi, Annu. Rev. Mater. Sci. 30, 545 (2000).

${ }^{14}$ Y. Yin and A. P. Alivisatos, Nature (London) 437, 664 (2005).

${ }^{15}$ R. Q. Zhang, Y. Lifshitz, and S. T. Lee, Adv. Mater. (Weinheim, Ger.) 15, 635 (2003).

${ }^{16}$ A. M. Morales and C. M. Lieber, Science 279, 208 (1998)

${ }^{17}$ T. Mårtensson, P. Carlberg, M. Borgstrom, L. Montelius, W. Seifert, and L. Samuelson, Nano Lett. 4, 699 (2004).

${ }^{18}$ J. Goldberger, A. I. Hochbaum, R. Fan, and P. Yang, Nano Lett. 6, 973 (2006).

${ }^{19}$ Y. F. Zhang, Y. H. Tang, N. Wang, D. P. Yu, C. S. Lee, I. Bello, and S. T. Lee, Appl. Phys. Lett. 72, 1835 (1998).

${ }^{20}$ D. P. Yu et al., Appl. Phys. Lett. 72, 3458 (1998).

${ }^{21}$ F. M. Kolb, H. Hofmeister, R. Scholz, M. Zacharias, U. Gosele, D. D. Ma, and S. T. Lee, J. Electrochem. Soc. 151, G472 (2004).

${ }^{22}$ J. Hu, Y. Bando, J. Zhan, Z. Liu, D. Golberg, and S. P. Ringer, Adv. Mater. (Weinheim, Ger.) 17, 975 (2005).

${ }^{23}$ N. D. Zakharov, P. Werner, G. Gerth, L. Schubert, L. Sokolov, and U. Gosele, J. Cryst. Growth 290, 6 (2006).

${ }^{24}$ J. Westwater, D. P. Gosain, S. Tomiya, S. Usui, and H. Ruda, J. Vac. Sci. Technol. B 15, 554 (1997). 
${ }^{25}$ Yi Cui, L. J. Lauhon, M. S. Gudiksen, J. Wang, and C. M. Lieber, Appl. Phys. Lett. 78, 2214 (2001).

${ }^{26}$ A. I. Hochbaum, R. Fan, R. He, and P. Yang, Nano Lett. 5, 457 (2005).

${ }^{27}$ S. Hofmann, C. Ducati, R. J. Neill, S. Piscanec, A. C. Ferrari, J. Geng, R. E. Dunin-Borkowski, and J. Robertson, J. Appl. Phys. 94, 6005 (2003).

${ }^{28}$ R. S. Wagner and W. C. Ellis, Appl. Phys. Lett. 4, 89 (1964).

${ }^{29}$ E. I. Givargizov, J. Cryst. Growth 31, 20 (1975).

${ }^{30}$ A. I. Persson, M. W. Larsson, S. Stenström, B. J. Ohlsson, L. Samuelson, and L. R. Wallenberg, Nat. Mater. 3, 677 (2004).

${ }^{31}$ K. A. Dick, K. Deppert, T. Martensson, B. Mandl, L. Samuelson, and W. Seifert, Nano Lett. 5, 761 (2005).

${ }^{32}$ A. Colli et al., Appl. Phys. Lett. 86, 153103 (2005).

${ }^{33}$ A. Colli, S. Hofmann, A. C. Ferrari, F. Martelli, S. Rubini, C. Ducati, A. Franciosi, and J. Robertson, Nanotechnology 16, S139 (2005).

${ }^{34}$ S. Hofmann, G. Csányi, A. C. Ferrari, M. C. Payne, and J. Robertson, Phys. Rev. Lett. 95, 036101 (2005).

${ }^{35}$ J. Liu et al., Science 280, 1253 (1998).

${ }^{36}$ A. Colli et al., AIP Conf. Proc. 723, 445 (2004).

${ }^{37}$ Y. F. Zhang, Y. H. Tang, C. Lam, N. Wang, C. S. Lee, I. Bello, and S. T. Lee, J. Cryst. Growth 212, 115 (2000).

${ }^{38}$ N. Wang, Y. F. Zhang, Y. H. Tang, C. S. Lee, and S. T. Lee, Appl. Phys. Lett. 73, 3902 (1998).

${ }^{39}$ B. Mandl, J. Stangl, T. Martensson, A. Mikkelsen, J. Eriksson, L. S. Karlsson, G. Bauer, L. Samuelson, and W. Seifert, Nano Lett. 6, 1817 (2006).

${ }^{40}$ H. D. Park, S. M. Prokes, M. E. Twigg, R. C. Cammarata, and A. C. Gaillot, Appl. Phys. Lett. 89, 223125 (2006).

${ }^{41}$ K. Byon, D. Tham, J. E. Fischer, and A. T. Johnson, Appl. Phys. Lett. 87, 193104 (2005).

${ }^{42}$ Z. W. Pan, Z. R. Dai, L. Xu, S. T. Lee, and Z. L. Wang, J. Phys. Chem. B 105, 2507 (2001)

${ }^{43}$ H. Y. Peng, Z. W. Pan, L. Xu, X. H. Fan, N. Wang, C. S. Lee, and S. T. Lee, Adv. Mater. (Weinheim, Ger.) 13, 317 (2001).

${ }^{44}$ M. A. Rafiq, A. Colli, P. Servati, Z. A. K. Durrani, A. C. Ferrari, W. I. Milne, and $\mathrm{H}$. Mizuta (unpublished).

${ }^{45}$ A. Colli, A. Fasoli, S. Hofmann, C. Ducati, J. Robertson, and A. C. Ferrari, Nanotechnology 17, 1046 (2006).

${ }^{46}$ Z. R. Dai, Z. W. Pan, and Z. L. Wang, Adv. Funct. Mater. 13, 9 (2003).

${ }^{47}$ D. Whang, S. Jin, Y. Wu, and C. M. Lieber, Nano Lett. 3, 1255 (2003).

${ }^{48}$ J. Z. He et al., Appl. Phys. Lett. 80, 1812 (2002).

${ }^{49}$ L. Dong, J. Bush, V. Chirayos, R. Solanki, J. Jiao, Y. Ono, J. F. Conley, and B. D. Ulrich, Nano Lett. 5, 2112 (2005).

${ }^{50}$ S. M. King, S. Chaure, J. Doyle, A. Colli, A. C. Ferrari, and W. J. Blau, Opt. Commun. 276, 305 (2007).

${ }^{51}$ M. J. O'Connell et al., Science 297, 593 (2002).

${ }^{52}$ S. Giordani, S. D. Bergin, V. Nicolosi, S. Lebedkin, M. M. Kappes, W. J. Blau, and J. N. Coleman, J. Phys. Chem. B 110, 15708 (2006).

${ }^{53}$ M. J. O'Connell et al., Chem. Phys. Lett. 342, 265 (2001).

${ }^{54}$ H. J. Snaith, G. L. Whiting, B. Sun, N. C. Greenham, W. T. S. Huck, and R. H. Friend, Nano Lett. 5, 1653 (2005).

${ }^{55}$ I. Gur, N. A. Fromer, C. P. Chen, A. G. Kanaras, and A. P. Alivisatos, Nano Lett. 7, 409 (2007)

${ }^{56}$ Y. Cui, Z. Zhong, D. Wang, W. U. Wang, and C. M. Lieber, Nano Lett. 3, 149 (2003).

${ }^{57}$ Y. Cui, X. Duan, J. Hu, and C. M. Lieber, J. Phys. Chem. B 104, 5213 (2000).

${ }^{58}$ Y. H. Tang, X. H. Sun, F. C. K. Au, L. S. Liao, H. Y. Peng, C. S. Lee, S. T. Lee, and T. K. Sham, Appl. Phys. Lett. 79, 1673 (2001).

${ }^{59} \mathrm{G}$. Zheng, W. Lu, S. Jin, and C. M. Lieber, Adv. Mater. (Weinheim, Ger.) 16, 1890 (2004).

${ }^{60}$ J. Y. Yu, S. W. Chung, and J. R. Heath, J. Phys. Chem. B 104, 11864 (2000).

${ }^{61}$ Y. Ahn, J. Dunning, and J. Park, Nano Lett. 5, 1367 (2005).

${ }^{62}$ W. M. Weber et al., Nano Lett. 6, 2660 (2006).

${ }^{63}$ D. N. Jarrett and L. Ward, J. Phys. D 9, 1515 (1976).
${ }^{64}$ E. Jiran and C. V. Thompson, J. Electron. Mater. 19, 1153 (1990).

${ }^{65}$ R. H. Doremus, J. Appl. Phys. 37, 2775 (1966).

${ }^{66}$ U. Kreibig and L. Genzel, Surf. Sci. 156, 678 (1985).

${ }^{67}$ L. Zhao, K. L. Kelly, and G. C. Schatz, J. Phys. Chem. B 107, 7343 (2003).

${ }^{68}$ M. Cantoro et al., Nano Lett. 6, 1107 (2006); M. Cantoro, S. Hofmann, S. Pisana, C. Ducati, A. Parvez, A. C. Ferrari, and J. Robertson, Diamond Relat. Mater. 15, 1029 (2006).

${ }^{69}$ A. L. Giermann and C. V. Thompson, Appl. Phys. Lett. 86, 121903 (2005).

${ }^{70}$ S. Hofmann, M. Cantoro, B. Kleinsorge, C. Casiraghi, A. Parvez, J. Robertson, and C. Ducati, J. Appl. Phys. 98, 034308 (2005).

${ }^{71}$ S. Pisana, M. Cantoro, A. Parvez, S. Hofmann, A. C. Ferrari, and J. Robertson, Physica E (Amsterdam) 37, 1 (2007).

${ }^{72}$ T. B. Massalski, Binary Alloy Phase Diagrams, 2nd ed. (ASM International, Materials Park, OH, 1990).

${ }^{73}$ J. Kikkawa, Y. Ohno, and S. Takeda, Appl. Phys. Lett. 86, 123109 (2005).

${ }^{74}$ P. Buffat and J. P. Borel, Phys. Rev. A 13, 2287 (1976).

${ }^{75}$ A. Jiang, N. Awasthi, A. N. Kolmogorov, W. Setyawan, A. Borjesson, K. Bolton, A. R. Harutyunyan, and S. Curtarolo, Phys. Rev. B 75, 205426 (2007).

${ }^{76}$ A. B. Greytak, L. J. Lauhon, M. S. Gudiksen, and C. M. Lieber, Appl. Phys. Lett. 84, 4176 (2004).

${ }^{77}$ T. I. Kamins, R. S. Williams, D. P. Basile, T. Hesjedal, and J. S. Harris, J. Appl. Phys. 89, 1008 (2001).

${ }^{78}$ Y. Wang, V. Schmidt, S. Senz, and U. Gosele, Nat. Nanotechnol. 1, 186 (2006).

${ }^{79}$ J. B. Hannon, S. Kodambaka, F. M. Ross, and R. M. Tromp, Nature (London) 440, 69 (2006).

${ }^{80}$ Y. Wu, Y. Cui, L. Huynh, C. J. Barrelet, D. C. Bell, and C. M. Lieber, Nano Lett. 4, 433 (2004).

${ }^{81}$ L. J. Lauhon, M. S. Gudiksen, and C. M. Lieber, Philos. Trans. R. Soc. London, Ser. A 362, 1247 (2004).

${ }^{82}$ L. Cao, L. Laim, C. Ni, B. Nabet, and J. E. Spanier, J. Am. Chem. Soc. 127, 13782 (2005).

${ }^{83}$ C. B. Jin, J. E. Yang, and M. H. Jo, Appl. Phys. Lett. 88, 193105 (2006).

${ }^{84} \mathrm{R}$. Weast, Handbook of Chemistry and Physics, 64th ed. (Chemical Rubber, Cleveland, 1983).

${ }^{85}$ S. Kodambaka, J. B. Hannon, R. M. Tromp, and F. M. Ross, Nano Lett. 6, 1292 (2006).

${ }^{86}$ X. H. Sun, N. B. Wong, C. P. Li, S. T. Lee, and T. K. Sham, J. Appl. Phys. 96, 3447 (2004).

${ }^{87}$ Y. F. Zhang, Y. H. Tang, N. Wang, C. S. Lee, I. Bello, and S. T. Lee, J. Cryst. Growth 197, 136 (1999).

${ }^{88}$ R. J. Barsotti, Jr., J. E. Fischer, C. H. Lee, J. Mahmood, C. K. W. Adu, and P. Eklund, Appl. Phys. Lett. 81, 2866 (2002).

${ }^{89}$ J. Hu, Y. Bando, J. Zhan, Z. Liu, D. Goldberg, and S. P. Ringer, Adv. Mater. (Weinheim, Ger.) 17, 975 (2005).

${ }^{90}$ A. B. Dalton et al., Nature (London) 423, 703 (2003).

${ }^{91}$ V. Scardaci, A. G. Rozhin, F. Hennrich, W. I. Milne, and A. C. Ferrari, Physica E (Amsterdam) 37, 115 (2007).

${ }^{92}$ G. Della Valle et al., Appl. Phys. Lett. 89, 231115 (2006).

${ }^{93} \mathrm{http}: / / \mathrm{www}$. diagenode.com/pages/bioruptor.html

${ }^{94}$ T. Pellegrino et al., Nano Lett. 4, 703 (2004).

${ }^{95}$ P. Beecher et al., J. Appl. Phys. (in press).

${ }^{96}$ S. W. Chung, J. Y. Yu, and J. R. Heath, Appl. Phys. Lett. 76, 2068 (2000).

${ }^{97}$ D. Wang, Y. L. Chang, Q. Wang, J. Cao, D. B. Farmer, R. G. Gordon, and H. Dai, J. Am. Chem. Soc. 126, 11602 (2004).

${ }^{98}$ S. M. Sze, Physics of Semiconductor Devices (Wiley, New York, 1981).

${ }^{99}$ A. M. Cowley and S. M. Sze, J. Appl. Phys. 36, 3212 (1965).

${ }^{100}$ C. A. Mead and W. G. Spitzer, Phys. Rev. 134, A713 (1964).

${ }^{101}$ M. O. Aboelfotoh and K. N. Tu, Phys. Rev. B 34, 2311 (1986).

${ }^{102}$ S. M. Koo, M. D. Edelstein, Q. Li, C. A. Richter, and E. M. Vogel, Nanotechnology 16, 1482 (2005). 